\title{
LAS CUENCAS DE LOS LAGOS TAR Y SAN MARTÍN (SANTA CRUZ, ARGENTINA) Y LA DINÁMICA DEL POBLAMIENTO HUMANO DEL SUR DE PATAGONIA: INTEGRACIÓN DE LOS PRIMEROS RESULTADOS ${ }^{1}$
}

\author{
JUAN BAUTISTA BELARDI", SILVANA ESPINOSA", FLAVIA CARBALLO MARINA"*; GUSTAVO

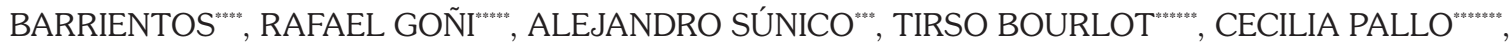

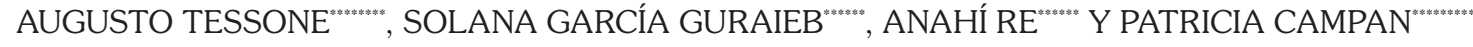

\section{RESUMEN}

Se presentan los primeros resultados arqueológicos sistemáticos obtenidos en las cuencas de los lagos Tar y San Martín (49 $7^{\prime} \mathrm{S}, 72^{\circ} 11^{\prime} \mathrm{O}$ ), focalizados sobre la distribución espacial y temporal del registro. La información se ordena siguiendo las principales unidades ecológicas (estepa, ecotono y bosque) con el fin de discutir la existencia de diferencias en el uso del espacio por parte de las poblaciones cazadoras recolectoras. A la vez, se brindan valores de isótopos estables $\left(\delta^{13} \mathrm{C}\right.$ y $\left.\delta^{15} \mathrm{~N}\right)$ obtenidos sobre muestras arqueofaunísticas de guanaco (Lama guanicoe) que permiten comenzar a delinear la ecología isotópica regional. Las diferencias en las distribuciones artefactuales articulan un primer modelo del paisaje arqueológico regional que muestra que las mayores intensidades de uso humano se registran en la margen este del lago Tar y en los alrededores del Cerro Cach Aike, decreciendo hacia el oeste (margen sur del lago San Martín). Las ocupaciones humanas se habrían iniciado alrededor de 9700 años AP, manteniéndose de manera discontinua hasta momentos históricos. Por último, se comparan los datos obtenidos con los disponibles en otras cuencas lacustres cordilleranas aledañas, integrando así un nuevo espacio a la discusión del poblamiento humano del suroeste de Patagonia.

PALABRAS CLAVES: Lagos Tar y San Martín, cazadores recolectores, distribuciones artefactuales. cronología, uso del espacio.

1 Una primera versión de este trabajo fue presentada en el XVI Congreso Nacional de Arqueología Argentina, San Salvador de Jujuy.

* Universidad Nacional de la Patagonia Austral.Unidad Académica Río Gallegos. CONICET. Santa Cruz, Argentina. silespi@ infovia.com.ar

* CONICET. Universidad Nacional de la Patagonia Austral. Unidad Académica Río Gallegos. Santa Cruz, Argentina.

*s* Universidad Nacional de la Patagonia Austral. Unidad Académica Río Gallegos. Santa Cruz, Argentina.

*e** CONICET. Universidad Nacional de La Plata y Universidad Nacional del Centro de la Provincia de Buenos Aires. La Plata, Provincia de Buenos Aires, Argentina.

**** Instituto Nacional de Antropología y Pensamiento Latinoamericano. Universidad de Buenos Aires y Universidad Nacional del Centro de la Provincia de Buenos Aires. Ciudad Autónoma de Buenos Aires, Argentina.

*s*s: CONICET. Instituto Nacional de Antropología y Pensamiento Latinoamericano. Ciudad Autónoma de Buenos Aires, Argentina.

${ }^{* 2 * * * s *}$ Instituto Multidisciplinario de Historia y Ciencias Humanas. Ciudad Autónoma de Buenos Aires, Argentina.

******** CONICET. INGEIS. Ciudad Autónoma de Buenos Aires, Argentina.

*s:sess** Museo Regional Provincial Padre Manuel Jesús Molina. Santa Cruz, Argentina. 


\title{
LAGOS TAR AND SAN MARTIN BASINS (SANTA CRUZ, ARGENTINA) AND THE DYNAMICS OF THE HUMAN PEOPLING OF SOUTHERN PATAGONIA: AN INTEGRATION OF PRELIMINARY RESULTS
}

\begin{abstract}
The aim of this paper is to present the first preliminary results of the systematic archaeological research carried out in the Lago Tar and Lago San Martin basins (49 $7^{\circ} \mathrm{S}, 72^{\circ} 11^{\prime} \mathrm{O}$ ), focusing on the distributional aspects of the record. In order to discuss patterned differences in the space use by prehistoric hunter-gatherers, the information is organized following the main ecologic units (steppe, forest, and the corresponding ecotone). Stable isotope data $\left(\delta^{13} \mathrm{C}\right.$ and $\left.\delta^{15} \mathrm{~N}\right)$ from guanaco (Lama guanicoe) bone samples are also reported as a first step in the understanding of the regional isotopic ecology. On the basis of some differences in the spacial distribution of artifacts it can be proposed that the higher intensity of human use was concentrated on the eastern shore of Lago Tar and around Cerro Cach Aike. Such intensity decreases westward (southern shore of the Lago San Martin). The occupation history of these spaces began around 9700 years BP, following a highly punctuated pattern until historic times. The paper ends with a comparison between the archaeological record of Lago Tar and Lago San Martin basins with other southern Patagonia cordillerean lacustrine basins in order to discuss the prehistoric peopling of the region.
\end{abstract}

KEYWORDS: Tar and San Martín lakes, hunter gatherers, artifactual distributions, chronology, land use.

\section{INTRODUCCIÓN}

El oeste patagónico se caracteriza por la presencia de extensas cuencas lacustres que, conformadas por la dinámica glaciaria del Cenozoico tardío (Rabassa y Coronato 2002), muestran importantes diferencias ambientales en un eje este-oeste. Las cuencas han sido empleadas como unidades de estudio arqueológicas en términos regionales. Así, a lo largo de los últimos 20 años, en la provincia Santa Cruz se han llevado a cabo trabajos en los lagos Pueyrredón, Posadas y Salitroso (entre otros, De Nigris et al. 2004; Goñi et al. 2000-2002); en el Parque Nacional Perito Moreno -cuencas de los lagos Belgrano y Burmeister- (entre otros, Goñi 1988; Aschero et al. 2005) y en el lago Argentino (entre otros, Belardi et al. 1992; Borrero 1998). No obstante, otras grandes cuencas carecen de trabajos sistemáticos, aunque se han realizado algunas observaciones arqueológicas, tal es el caso de los lagos Buenos Aires (Gradin 1996), Viedma (Belardi y Caracotche 2005; Menghin 1957) y Tar-San Martín (Belcaguy 1983; Molinari 1983; Molinari y Espinosa 1999; Espinosa et al. 2007).
El objetivo de este trabajo es dar a conocer los primeros resultados arqueológicos sistemáticos para la cuenca de los lagos Tar y San Martín, integrándola a la discusión de la dinámica poblacional del oeste patagónico. Dichos resultados fueron obtenidos en las campañas de los años 2006 y 2007 y enfatizan la distribución espacial y temporal del registro arqueológico en relación con las principales unidades ecológicas (estepa, ecotono y bosque). Con esta información se conforma un modelo sobre el paisaje arqueológico regional que permite comenzar a evaluar la existencia de diferencias en el uso del espacio por parte de las poblaciones cazadoras recolectoras. A la vez, junto con los datos cronológicos obtenidos sobre muestras de guanaco (Lama guanicoe), se brinda la correspondiente información isotópica $\left(\delta^{13} \mathrm{C}\right.$ y $\left.\delta^{15} \mathrm{~N}\right)$ con el fin de iniciar el desarrollo de la ecología isotópica regional. Todos estos resultados constituyen la base de posteriores trabajos a realizar en el marco de los proyectos en curso.

En primer lugar, se presentará una caracterización ambiental de la región y de sus antecedentes arqueológicos. Luego, se introducirán los nuevos resultados, focalizados sobre el registro lítico, de acuerdo con los distintos sectores trabajados. A 
partir de esta información, se discutirán las implicaciones de las primeras evidencias de ocupación regional y de las variaciones en la intensidad de uso del espacio, a la luz de las hipótesis de marginalidad propuesta por Borrero (2004), del uso residencial de los fondos de cuenca formulada por Goñi et al. (2000-2002) y de las estrategias logísticas implementadas en ambientes tales como las mesetas (Belardi y Goñi 2006; Borrero 1994-1995) y el bosque (entre otros, Espinosa 2000, 2002). A la vez, se explorará la integración de la región de los lagos Tar y San Martín dentro de un marco mayor de interacción y circulación de bienes e información (Belardi y Goñi 2006; Espinosa et al. 2007) y se discutirá el patrón de poblamiento de estas cuencas en el contexto del poblamiento de la Patagonia (Borrero 1994-1995).

\section{CARACTERÍSTICAS AMBIENTALES DE LA REGIÓN}

Las cuencas de los lagos Tar y San Martín se encuentran en el suroeste de la provincia de Santa Cruz (49 $7^{\circ} \mathrm{S}, 72^{\circ} 11^{\prime} \mathrm{O}$ ), a aproximadamente 300 msnm (Fig. 1). Han sido principalmente modeladas por la acción glaciaria, tienen una orientación noroeste-sudeste y están circundadas por diferentes sistemas de morenas (Bonarelli y Nágera 1921; Aüer y Cappannini 1957; Rabassa y Coronato 2002). Hacia el oeste se encuentran limitadas por el Campo de Hielo Sur, mientras que hacia el norte por la meseta del Cardiel-Chico y hacia el sur por las mesetas que las comunican con el lago Viedma.

En la región se destaca una importante diferenciación ambiental que, desde el este, incluye semidesierto y estepa arbustiva (alrededores del lago Tar y del cerro Cach Aike), estepa graminosa (lago San Martín), ecotono bosque-estepa y bosque (caracterizado por la presencia de Nothofagus), en el oeste del lago San Martín y en las penínsulas, Maipú y Chacabuco (ver Bamonte 2008). Ambas cuencas presentan un alto grado de erosión (Aüer y Cappannini 1957), característica que se observa principalmente en la ladera oriental del fondo de cuenca entre la Ea. La Federica y el oeste del Co. Cach Aike (Fig. 1) y las zonas bajas de la margen sudeste del lago Tar. A diferencia de este último, el San Martín es encajonado, lo que deja poca disponibilidad de espacio para ser usado como campos de invernada (com. pers. del personal de las estancias).
Ambas cuencas se ubican en el extremo oeste del eje de circulación natural para las poblaciones humanas, que es el valle del río Chalía, que corre en sentido NO-SE y están próximas a otro importante eje de circulación, esta vez en dirección N-S, como es el largo corredor sobre el que se emplaza la actual Ruta Nacional $N^{\circ} 40$. A la vez, sobre la margen este del lago Tar, desembocan los ríos Tar y Meseta (al norte y sur, respectivamente) que actúan como rutas naturales de circulación uniendo la meseta del Cardiel Chico y la del lago Viedma.

Se cuenta con información paleoambiental que describe las características para el ecotono bosqueestepa durante el Holoceno medio. El estudio de un perfil polínico proveniente de la Ea. La Tercera (margen sur del lago San Martín) indica que, con anterioridad a 7.540 años A.P., predominaba una estepa graminosa, con alta disponibilidad hídrica con precipitaciones anuales entre los 500 y los 300 $\mathrm{mm}$. Para el lapso comprendido entre 7.540 años A.P. y 5.700 años A.P., se dieron condiciones menos húmedas. Asimismo, en este período se evidencia un mayor desarrollo del bosque de Nothofagus por un aumento de la temperatura. Al respecto, cabe mencionar que el límite del bosque durante el Holoceno no se extendió más de $10 \mathrm{~km}$. de la línea actual (Bamonte 2008). Desde 5.700 años A.P. y hasta 5500 años A.P., la disminución de arbustos y el aumento de pastos señalan un intervalo con mayor humedad. Luego, y hasta 4.000 años A.P., habrían regresado las condiciones de menor humedad. Los datos disponibles indican que se habría instaurado una estepa graminosa y arbustiva, con precipitaciones que oscilarían entre los 200 y los $500 \mathrm{~mm}$ anuales, sin mostrar analogías con el bosque ni con el semidesierto (Bamonte 2008). Por otra parte, también en la Ea. La Tercera se realizó el estudio de una turbera cuyos resultados coinciden con los citados, al mostrar una alternancia entre períodos húmedos y secos (Aüer y Cappannini 1957). En concordancia con los registros sedimentológicos del lago Cardiel, hay evidencias de una mayor estacionalidad durante el Holoceno medio y tardío (Bamonte 2008; Gilli et al. 2005). Por último, deben considerarse los avances neoglaciales ocurridos entre 8.500-7.500 años A.P. y entre 5.800-5.500 años A.P. (Wenzens 1999), que coinciden con los dos momentos de mayor disponibilidad de humedad documentados para el espacio bajo análisis (Bamonte 2008). 

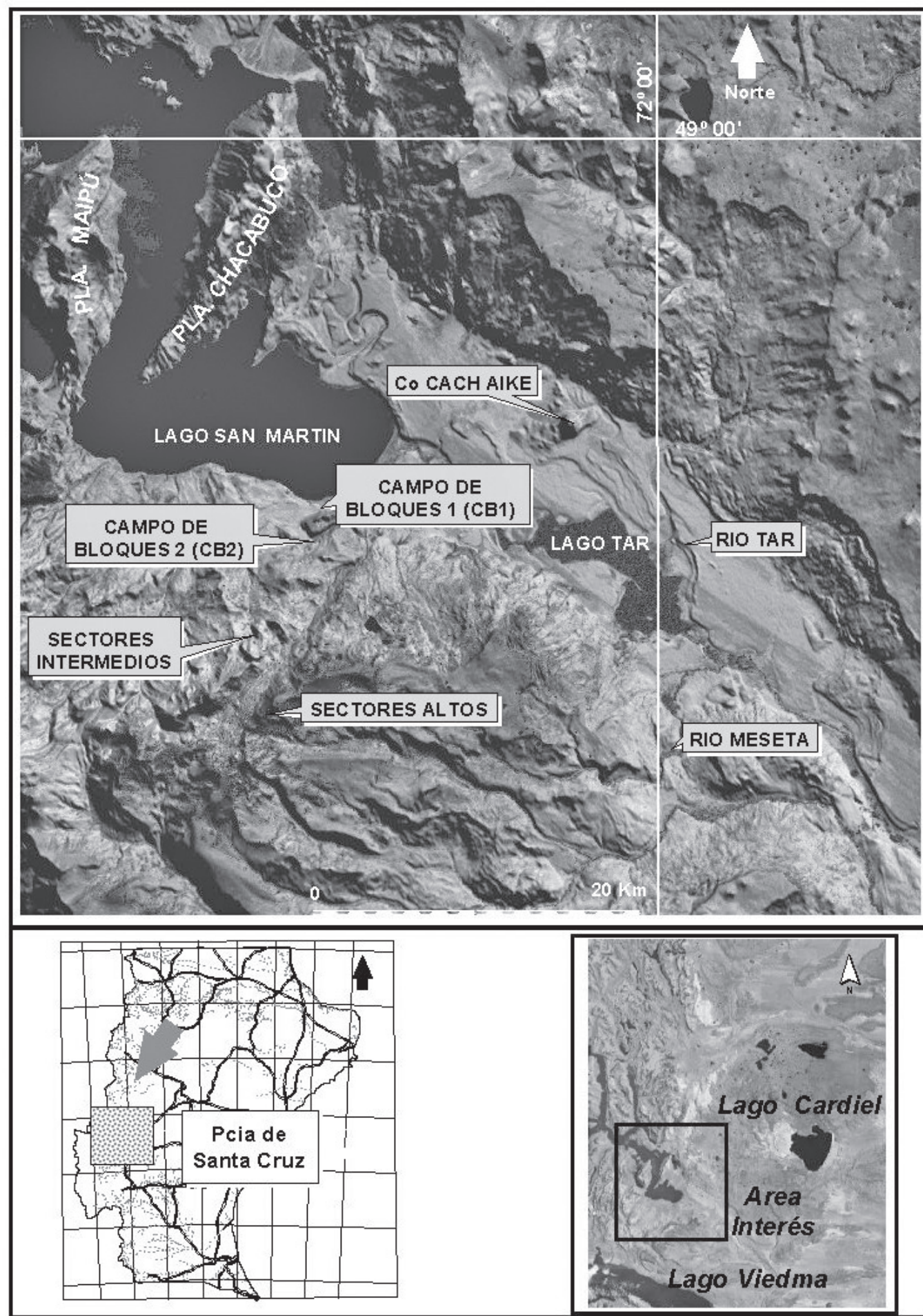

Fig. 1. Ubicación de los distintos sectores trabajados. 
A lo largo de un eje comprendido por el lago San Martín y las nacientes del río Chalía, existen dos grandes áreas con diferente disponibilidad de materias primas líticas. La primera comprende desde el río Diablo (margen sudoeste del lago San Martín) hasta las nacientes del río Chalía. Aquí, las rocas disponibles provendrían principalmente de los sedimentos glacifluviales, de las sedimentitas cretácicas y de los afloramientos y mantos lávicos básicos que coronan las mesetas. Es por ello que los basaltos y andesitas del Terciario son las rocas con mayor disponibilidad y aptitud. La segunda área se ubica al oeste del río Diablo, donde dominan principalmente los afloramientos de rocas que conforman el Complejo El Quemado, cuyas texturas, durezas y grado de silicificación e incluso el ambiente geológico en el que se formaron, permiten suponer una amplia disponibilidad o posibilidad de hallazgo. En este sector se encuentran rocas y silicificaciones provenientes de vetas y vetillas, que serían aptas para la talla (tobas dacíticas verdes y gris verdoso de grano muy fino y lutitas negras). También hay disponibilidad de areniscas y concreciones provenientes de las sedimentitas cretácicas. Por último, en ambas áreas existen clastos constituyentes de los depósitos glacifluviales, los que son aptos para la talla. En este marco se destaca el istmo de la Península Maipú, donde se registró la disponibilidad de toba silicificada verde (Espinosa et al. 2009).

\section{LA INFORMACIÓN ARQUEOLÓGICA PRECEDENTE}

Los primeros trabajos arqueológicos de las cuencas de los lagos Tar y San Martín fueron realizados por R. Molinari (1983) y H. Belçaguy (1983). Estas investigaciones se centraron en el análisis tecnotipológico de los materiales asistemáticamente recolectados por Horst Thierauf en los alrededores de la Ea. Cach Aike. Dichos materiales fueron posteriormente reanalizados en el marco del presente proyecto, ampliando la perspectiva espacial al incluir otros conjuntos de la región (Espinosa et al. 2007). En este contexto, se analizaron 807 artefactos líticos obtenidos en 54 sitios/concentraciones a cielo abierto de sectores bajos de estepa provenientes del lago Tar, alrededores del cerro Cach Aike y del lago San Martín. Las mayores densidades se registraron sobre el lado oeste del cerro Cach Aike. Las rocas más utilizadas para la confección de artefactos fueron las silíceas (25,8\%), los basaltos (11\%), la obsidiana (10,7\%), la calcedonia $(9,2 \%)$ y el ópalo (9,3\%). Todas estas rocas están disponibles localmente, con la excepción de la obsidiana, que proviene de la Pampa del Asador (Espinosa y Goñi 1999; Molinari y Espinosa 1999; Stern 1999; ver Belardi et al. 2006), ubicada a $150 \mathrm{~km}$ lineales al $\mathrm{NE}$ de la región de estudio. En cuanto a las clases artefactuales, predominan los raspadores $(22,7 \%)$, desechos de talla $(20,4 \%)$, raederas $(17,5 \%)$ y puntas de proyectil (9,3\%). Si bien existieron sesgos en la conformación de la colección, principalmente con respecto a los desechos de talla, la jerarquización artefactual se ajusta a la registrada en conjuntos provenientes de las cuencas próximas como la de los lagos Cardiel y Strobel (Espinosa et. al. 2007).

Se destaca la amplia distribución espacial de la tecnología bifacial, sobre todo en el empleo de bifaces en estadios avanzados de manufactura (sensu Nami 1986) como formas base para la confección de raederas. Dado que los bifaces presentan diseños confiables, versátiles y transportables -sensu Nelson 1991- se planteó que estas piezas podrían estar relacionadas con los momentos iniciales de poblamiento de la región. Sobre la base de las características tipológicas y tecnológicas de las puntas de proyectil, la presencia de cerámica decorada, una placa grabada y una "copa lítica" (Belçaguy 1983), se ubicó cronológicamente a una parte de la muestra artefactual en momentos tardíos de ocupación del sur de Patagonia (últimos 2.500 años A.P.) (Espinosa et al. 2007). Se dató un ejemplar de Aulacomya atra atra recuperada por $\mathrm{H}$. Thierauf en un sitio de la margen sur del lago San Martín. Dado que esta datación fue publicada en el citado trabajo sin su correspondiente corrección, aquí se la brinda corregida, por lo que el fechado es de 1.090 \pm 40 años A.P. (UGAMS 01369). Si se considera un efecto reservorio de 400 años (Cordero et al. 2003, Tabla 2), el fechado es de 690 años A.P. (ver comentarios en Espinosa et al. 2007). La información histórica disponible indica la persistencia en el área de poblaciones cazadoras-recolectoras en momentos de contacto y aún entrado el siglo XX (ver comentarios de la Sra. Margarita Quintillán en Casiragui y Caorsi 2000). 
Tabla 1. Transectas en la cuenca del lago Tar.

\begin{tabular}{|c|c|c|c|c|c|}
\hline N Transectas & $\mathrm{N}$ muestreos & Superficie $\mathrm{m}^{2}$ & $\begin{array}{c}\mathrm{N} \text { y } \% \text { muestreos } \\
\text { con hallazgos }\end{array}$ & $\begin{array}{l}\mathrm{N} \text { artefactos / } \\
\text { densidades } \mathrm{m}^{2}\end{array}$ & Visibilidad \\
\hline \multicolumn{6}{|c|}{ Margen Norte } \\
\hline 5 & 91 & 131.000 & $8(8,79 \%)$ & $\begin{array}{c}9 / \\
0,00006 \\
\end{array}$ & Muy Buena \\
\hline \multicolumn{6}{|c|}{ Margen Este } \\
\hline 4 & 62 & 127.500 & $17(27,41 \%)$ & $\begin{array}{c}77 / \\
0,0006\end{array}$ & Muy Buena \\
\hline \multicolumn{6}{|c|}{ Margen Sudeste } \\
\hline 4 & 48 & 48.000 & $2(4,16 \%)$ & $\begin{array}{c}2 / \\
0,00004\end{array}$ & Muy Buena \\
\hline \multicolumn{6}{|c|}{ Margen Oeste } \\
\hline 3 & 42 & 37.000 & 0 & 0 & Muy buena \\
\hline
\end{tabular}

\section{OBTENCIÓN Y PRESENTACIÓN DE LA INFORMACIÓN}

Se relevaron las márgenes del lago Tar y la margen sur del lago San Martín (Fig. 1). Los resultados alcanzados se presentarán siguiendo un eje este-oeste que se corresponde con el lineamiento estepa-bosque. Sobre la base de considerar al registro arqueológico como una distribución más o menos continua en el espacio, con variaciones en su densidad, se implementaron estudios distribucionales utilizando transectas continuas (entre otros, Dunnell y Dancey 1983; Foley 1981). La creciente desertificación, tempranamente señalada por Aüer y Cappannini (1957) como uno de los principales problemas ambientales de la región, hace que las condiciones de visibilidad arqueológica en la estepa sean muy buenas, por lo que la implementación de transectas resulta adecuada. Por el contrario, en el interior del bosque se realizaron búsquedas dirigidas en los espacios que, como las cicatrices de erosión, poseen buena visibilidad (ver Belardi y Campan 1999; Borrero y Muñoz 1999; Espinosa et al. 2009). Las transectas permitieron obtener frecuencias artefactuales que se usaron para el cálculo de densidades por $\mathrm{m}^{2}$. Por otra parte, se evaluó el porcentaje de muestreos sin hallazgos, con el fin de indicar las diferencias en la intensidad de depositación de artefactos en un espacio dado. Con respecto a los artefactos líticos se señalaron las frecuencias por clases artefactuales (ver Aschero 1975 rev. 1983) y los tipos de materias primas empleadas.

A su vez, se iniciaron excavaciones en sectores acotados del espacio en los cuales se constató la presencia de materiales en estratigrafía. También se procedió, mediante búsquedas dirigidas, al relevamiento y obtención de muestras biológicas humanas.

Por otra parte, con el fin de comenzar a delinear la ecología isotópica regional, se obtuvieron valores de $\delta^{13} \mathrm{C}$ y $\delta^{15} \mathrm{~N}$ a partir de muestras arqueofaunísticas (guanaco) que fueron a su vez datadas por AMS. La extracción del colágeno y los análisis respectivos se llevaron a cabo en el Center for Applied Isotope Studies, University of Georgia (CAIS UGA).

Tabla 2: Margen norte del lago Tar. Transectas Frecuencias y porcentajes de clases artefactuales por materia prima.

Referencias: DTI: desecho de talla interno. Nu: núcleo, Rp. Raspador y Bi: biface.

\begin{tabular}{|c|c|c|c|c|c|c|}
\hline \multirow[b]{2}{*}{ Materias primas } & \multicolumn{4}{|c|}{ Artefactos } & \multirow[b]{2}{*}{ Totales } & \multirow[b]{2}{*}{$\%$} \\
\hline & DTI & $\mathrm{Nu}$ & $\mathrm{Rp}$ & $\mathrm{Bi}$ & & \\
\hline Basalto & 1 & 1 & 0 & 0 & 2 & 22,2 \\
\hline Obsidiana & 2 & 0 & 0 & 1 & 3 & 33,3 \\
\hline Riolita & 0 & 0 & 1 & 0 & 1 & 11,1 \\
\hline Toba & 3 & 0 & 0 & 0 & 3 & 33,3 \\
\hline Totales & 6 & 1 & 1 & 1 & 9 & \\
\hline$\%$ & 66,6 & 11,1 & 11,1 & 11,1 & & \\
\hline
\end{tabular}


Tabla 3. Río Tar "Concentración Transecta". Frecuencias y porcentajes de clases artefactuales por materia prima. Referencias: DTE: desecho de talla externo, DTI: desecho de talla interno, Nu: núcleo, Rp: raspador, Yu: yunque, Bo: bola y AFS: artefacto de formatización sumaria.

\begin{tabular}{|c|c|c|c|c|c|c|c|c|c|}
\hline & \multicolumn{7}{|c|}{ Artefactos } & & \\
\hline Materias primas & DTE & DTI & $\mathrm{Nu}$ & $\mathrm{Rp}$ & $\mathrm{Yu}$ & Bo & AFS & Totales & $\%$ \\
\hline Andesita & 0 & 0 & 0 & 0 & 1 & 1 & 0 & 2 & 10,5 \\
\hline Dacita & 3 & 0 & 2 & 0 & 0 & 0 & 0 & 5 & 26,3 \\
\hline Limonita & 1 & 0 & 0 & 0 & 0 & 0 & 0 & 1 & 5,2 \\
\hline Lutita & 2 & 4 & 0 & 0 & 0 & 0 & 1 & 7 & 36,8 \\
\hline Obsidiana & 0 & 1 & 0 & 0 & 0 & 0 & 0 & 1 & 5,2 \\
\hline Sílice & 0 & 1 & 0 & 2 & 0 & 0 & 0 & 3 & 15,7 \\
\hline Totales & 6 & 6 & 2 & 2 & 1 & 1 & 1 & 19 & \\
\hline$\%$ & 31,5 & 31,5 & 10,5 & 10,5 & 5,2 & 5,2 & 5,2 & & \\
\hline
\end{tabular}

\section{1-Lago Tar}

Los trabajos se iniciaron en torno al lago Tar y en la cuenca inferior del río Tar. En principio, las transectas se plantearon sobre la parte posterior de las morenas que endican al lago en su margen este, donde se observaron las mayores densidades artefactuales y el mayor porcentaje de muestreos con hallazgos. En los muestreos efectuados sobre las márgenes norte, sureste y oeste, las frecuencias son, por el contrario, sumamente bajas a nulas (Tabla 1).

En la margen norte del lago Tar sólo se recuperaron nueve artefactos manufacturados en rocas locales (sensu Meltzer 1989) y en obsidiana (Tabla 2). No obstante estas bajas frecuencias, sobre la margen este y aguas arriba del río Tar, se localizó una con- centración de materiales líticos en una superficie de $224 \mathrm{~m}^{2}$. La misma fue denominada "Concentración Transecta" (Belardi et al. 2009) y se detalla en la Tabla 3. Este conjunto está compuesto por seis clases artefactuales; los desechos de talla manufacturados en materias primas locales son mayoritarios.

Tal como se indicara, la margen este del lago Tar presenta un comportamiento diferente al resto, lo que se manifiesta tanto en las clases artefactuales presentes, como en el tipo y porcentaje de materias primas empleadas en su manufactura, destacándose el alto porcentaje de obsidiana (Tabla 4). Por último, ostenta el mayor porcentaje de muestreos con hallazgos $(27,41 \%)$ lo que es concordante con una distribución más continua de artefactos y evidencia el uso más intenso por parte de las poblaciones humanas de ese sector del lago (Fig. 2).

Tabla 4: Margen este del lago Tar. Transectas. Frecuencias y porcentajes de clases artefactuales por materia prima. Referencias: Madera sil.: madera silicificada, DTE: desecho de talla externo, DTI: desecho de talla interno, Un: núcleo, Rp: raspador, PP: punta de proyectil, AFS: artefacto de formatización sumaria, Rd: raedera, FAF: artefacto de formatización sumaria y $\mathrm{Ch}+\mathrm{Rd}$ : cuchillo + raedera.

\begin{tabular}{|c|c|c|c|c|c|c|c|c|c|c|c|}
\hline \multirow[b]{2}{*}{ Materias primas } & \multicolumn{9}{|c|}{ Artefactos } & \multirow[b]{2}{*}{ Totales } & \multirow[b]{2}{*}{$\%$} \\
\hline & DTE & DTI & $\mathrm{Nu}$ & $\mathrm{Rp}$ & PP & $\mathrm{Rd}$ & $\mathrm{Ch}+\mathrm{Rd}$ & FAF & AFS & & \\
\hline Basalto & 0 & 3 & 0 & 0 & 0 & 0 & 0 & 0 & 0 & 3 & 4 \\
\hline Calcedonia & 0 & 1 & 0 & 2 & 0 & 0 & 0 & 0 & 0 & 3 & 4 \\
\hline Cuarzo & 0 & 1 & 0 & 0 & 0 & 0 & 0 & 0 & 0 & 1 & 1,3 \\
\hline Dacita & 0 & 2 & 0 & 0 & 0 & 0 & 0 & 0 & 0 & 2 & 2,6 \\
\hline Limolita & 0 & 1 & 0 & 0 & 0 & 0 & 0 & 0 & 0 & 1 & 1,3 \\
\hline Lutita & 0 & 2 & 0 & 0 & 0 & 0 & 0 & 0 & 0 & 2 & 2,6 \\
\hline Madera sil. & 0 & 1 & 0 & 0 & 0 & 0 & 0 & 0 & 0 & 1 & 1,3 \\
\hline Obsidiana & 3 & 19 & 1 & 0 & 4 & 0 & 0 & 0 & 0 & 27 & 36 \\
\hline Riolita & 0 & 0 & 0 & 0 & 0 & 0 & 0 & 0 & 1 & 1 & 1,3 \\
\hline Sílice & 0 & 20 & 0 & 1 & 1 & 1 & 0 & 1 & 0 & 24 & 32 \\
\hline Toba & 0 & 11 & 0 & 0 & 0 & 0 & 1 & 0 & 0 & 12 & 16 \\
\hline Totales & 3 & 61 & 1 & 3 & 5 & 1 & 1 & 1 & 1 & 77 & \\
\hline$\%$ & 4 & 81,3 & 1,3 & 1,3 & 6,6 & 1,3 & 1,3 & 1,3 & 1,3 & & \\
\hline
\end{tabular}




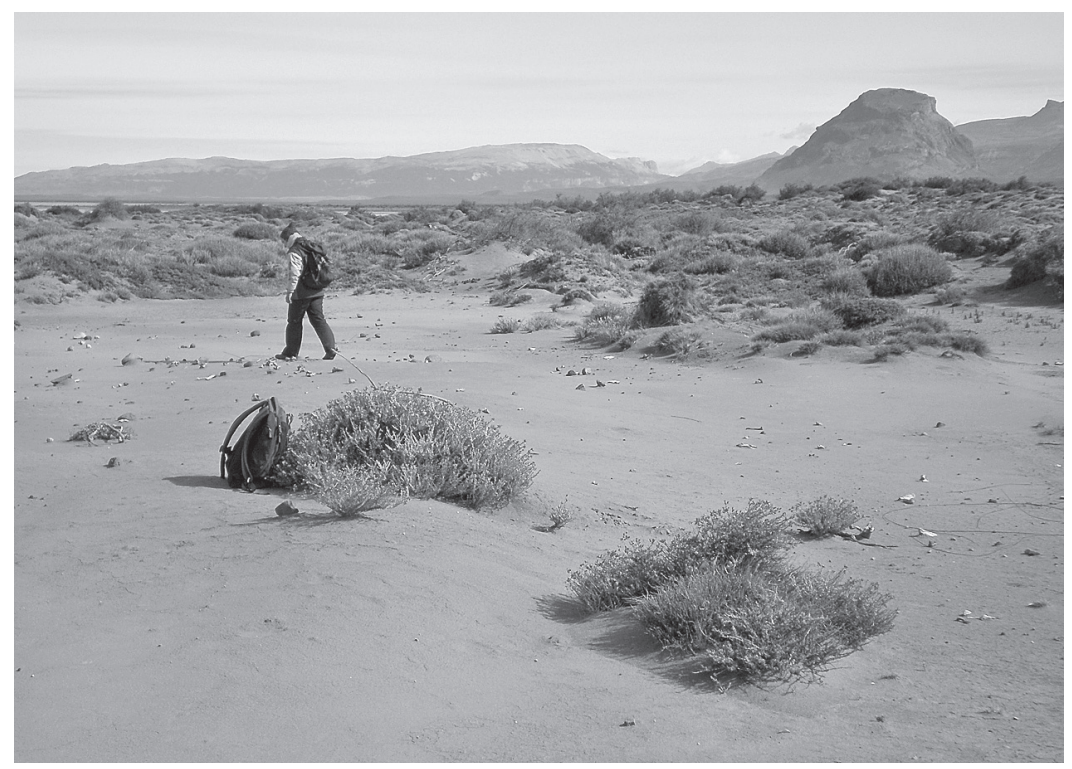

Fig. 2. Materiales arqueológicos sobre la margen este del lago Tar. Hacia el fondo de la imagen se destaca el cerro Cach Aike.

En inmediaciones de la Ea. Río Meseta (Fig. 1), se registró el sitio Río Meseta 1 (80 m x 24 m. en sentido E-O). Esta concentración de materiales se localiza sobre la superficie de un médano deflacionado que apoya sobre la base de una morena y está disectado por un camino interno. Se trata de un conjunto caracterizado por una alta frecuencia de desechos de talla y de restos de guanaco, mayoritariamente epífisis de huesos largos. Se obtuvo una datación de $4.430 \pm 50$ años A.P; $\delta^{13} C$ : $-19,33$;

Tabla 5. Margen este lago Tar. Río Meseta 1. Frecuencias y porcentajes de clases artefactuales por materia prima.

Referencias: Madera sil: Madera silicificada, Toba sil. v.: Toba silicificada verde, DTE: desecho de talla externo, DTI: desecho de talla interno, Nu: núcleo, Rp: raspador, Bo: bola, De: denticulado y Per: percutor, FAF: fragmento de artefacto formatizado y AFS: artefacto de formatización sumaria.

\begin{tabular}{|c|c|c|c|c|c|c|c|c|c|c|c|}
\hline \multirow[b]{2}{*}{ Materias primas } & \multicolumn{9}{|c|}{ Artefactos } & \multirow[b]{2}{*}{ Totales } & \multirow[b]{2}{*}{$\%$} \\
\hline & DTE & DTI & $\mathrm{Nu}$ & $\mathrm{Rp}$ & Bo & $\mathrm{De}$ & Per & FAF & AFS & & \\
\hline Arenisca & 1 & 3 & 0 & 0 & 1 & 0 & 0 & 0 & 0 & 5 & 3,3 \\
\hline Andesita & 0 & 0 & 1 & 0 & 0 & 0 & 0 & 0 & 0 & 1 & 0,6 \\
\hline Basalto & 6 & 6 & 1 & 0 & 0 & 1 & 0 & 0 & 1 & 15 & 9,9 \\
\hline Calcedonia & 0 & 3 & 1 & 1 & 0 & 0 & 0 & 0 & 0 & 5 & 3,3 \\
\hline Dacita & 0 & 16 & 2 & 0 & 0 & 0 & 1 & 0 & 0 & 19 & 12,5 \\
\hline Diabasa & 0 & 1 & 1 & 0 & 1 & 0 & 0 & 0 & 0 & 3 & 1,9 \\
\hline Granito & 1 & 0 & 1 & 0 & 0 & 0 & 0 & 0 & 0 & 2 & 1,3 \\
\hline Jaspe & 1 & 0 & 1 & 0 & 0 & 0 & 0 & 0 & 0 & 2 & 1,3 \\
\hline Limolita & 0 & 5 & 4 & 0 & 0 & 0 & 0 & 0 & 0 & 9 & 5,9 \\
\hline Lutita & 1 & 1 & 0 & 0 & 0 & 0 & 0 & 0 & 0 & 2 & 1,3 \\
\hline Madera sil & 0 & 0 & 1 & 0 & 0 & 0 & 0 & 0 & 0 & 1 & 0,6 \\
\hline Obsidiana & 3 & 12 & 0 & 1 & 0 & 0 & 0 & 1 & 0 & 17 & 11,2 \\
\hline Ópalo & 0 & 2 & 0 & 1 & 0 & 0 & 0 & 0 & 0 & 3 & 1,9 \\
\hline Riolita & 4 & 14 & 1 & 0 & 1 & 0 & 0 & 0 & 0 & 20 & 13,2 \\
\hline Sílice & 3 & 23 & 2 & 1 & 0 & 0 & 0 & 2 & 0 & 31 & 20,5 \\
\hline Toba & 0 & 12 & 0 & 0 & 0 & 0 & 0 & 0 & 0 & 12 & 7,9 \\
\hline Toba sil. v. & 3 & 1 & 0 & 0 & 0 & 0 & 0 & 0 & 0 & 4 & 2,6 \\
\hline Totales & 23 & 99 & 16 & 4 & 3 & 1 & 1 & 3 & 1 & 151 & \\
\hline$\%$ & 15,2 & 65,5 & 10,5 & 2,6 & 1,9 & 0,6 & 0,6 & 1,9 & 0,6 & & \\
\hline
\end{tabular}


$\delta^{15} \mathrm{~N}: 5,61$ (UGAMS 1689) sobre un tarsal de guanaco -articulado con el calcáneo, que presentaba huellas de corte-.

Aquí también se recuperó arqueofauna, con una baja representación de especies, y predominio del guanaco. Se observa una mayor frecuencia del esqueleto apendicular por sobre el axial, aunque en algunos conjuntos está presente todo el esqueleto. Los perfiles anatómicos están conformados por aquellas partes de alto valor de carne. Lo señalado es concordante con las primeras etapas del procesamiento de presas. Asimismo, la alta frecuencia de diáfisis fracturadas con negativos de impacto y marcados perimetrales se relacionaría con la extracción de médula ósea. El perfil etario de los individuos recuperados es de entre uno y tres meses y un año; esto permite posicionar las ocupaciones durante los meses de verano. El choique (Pterocnemia pennata) también está presente, aunque en baja frecuencia y sólo en algunos conjuntos.

Los materiales líticos fueron recuperados en cinco cuadrículas de $4 \mathrm{~m}^{2}$ cada uno (Tabla 5). Para su manufactura se empleó una gran diversidad de rocas locales, entre otras las tobas y las silíceas. No obstante, también se utilizó la obsidiana. Hay evidencias de eventos de talla y manufactura de artefactos en todas las rocas registradas que, junto con la alta frecuencia de núcleos recuperados, indica la realización de actividades de talla en el lugar.

Sobre el sector este del lago desembocan los ríos Tar y Meseta (Fig. 1). Ambos conforman los caminos de menor costo que articulan con las mesetas y, en el caso del primero de ellos, también podría ser una vía de entrada a la región de la obsidiana de Pampa del Asador (ver desarrollo en Belardi et al. 2009).

Por otra parte, en la margen sudeste del lago -en proximidades de la Ea. Lago Tar (Fig. 1)las transectas mostraron una muy baja frecuencia de artefactos, ya que sólo se registraron una lasca interna de obsidiana y otra de basalto. No obstante, y como resultado de muestreos dirigidos en lugares de muy buena visibilidad (potreros de la estancia), se detectaron tres concentraciones denominadas Lago Tar 1, con 50 artefactos distribuidos en una superficie de $720 \mathrm{~m}^{2}$, Lago Tar 2, que ocupa una superficie de $1012 \mathrm{~m}^{2}$ y en la que se recolectaron 51 artefactos, y Lago Tar 3, con 17 artefactos en $640 \mathrm{~m}^{2}$ (Tabla 6).

Se recuperaron ocho clases artefactuales manufacturadas en materias primas locales y en obsidiana. Uno de los núcleos y dos lascas internas son de toba

Tabla 6. Sumatoria Sitos Lago Tar 1, 2 y 3: Frecuencias y porcentajes de clases artefactuales por materia prima. Referencias: Toba sil: Toba silicificada, Indet.: Indeterminada, DTE: desecho de talla externo, DTI: desecho de talla interno,

$\mathrm{Nu}$ : núcleo, Rp: raspador, Yu: yunque, Mo: Molino, Bo: bola y Rd: raedera y AFS: artefacto de formatización sumaria.

\begin{tabular}{|c|c|c|c|c|c|c|c|c|c|c|c|}
\hline \multirow[b]{2}{*}{ Materias primas } & \multicolumn{9}{|c|}{ Artefactos } & \multirow[b]{2}{*}{ Totales } & \multirow[b]{2}{*}{$\%$} \\
\hline & DTE & DTI & $\mathrm{Nu}$ & $\mathrm{Rp}$ & $\mathrm{Yu}$ & Mo & Bo & $\mathrm{Rd}$ & AFS & & \\
\hline Arenisca & 1 & 3 & 0 & 0 & 0 & 0 & 0 & 0 & 0 & 4 & 3,3 \\
\hline Basalto & 0 & 29 & 6 & 0 & 1 & 0 & 0 & 0 & 0 & 37 & 31,3 \\
\hline Calcedonia & 1 & 3 & 1 & 1 & 0 & 0 & 0 & 0 & 0 & 6 & 5 \\
\hline Granito & 0 & 0 & 0 & 0 & 1 & 1 & 0 & 0 & 0 & 1 & 0,8 \\
\hline Limolita & 0 & 10 & 1 & 0 & 0 & 0 & 0 & 0 & 0 & 11 & 9,3 \\
\hline Lutita & 0 & 6 & 0 & 0 & 0 & 0 & 0 & 0 & 0 & 6 & 5 \\
\hline Obsidiana & 1 & 1 & 1 & 0 & 0 & 0 & 0 & 0 & 0 & 3 & 2,5 \\
\hline Sílice & 0 & 7 & 2 & 2 & 0 & 0 & 0 & 0 & 1 & 12 & 10,1 \\
\hline Toba & 2 & 10 & 3 & 0 & 0 & 0 & 0 & 0 & 1 & 16 & 13,9 \\
\hline Toba sil. & 0 & 13 & 2 & 2 & 0 & 0 & 0 & 1 & 0 & 18 & 15,2 \\
\hline Indet. & 0 & 2 & 1 & 0 & 0 & 0 & 1 & 0 & 0 & 4 & 3,3 \\
\hline Totales & 5 & 84 & 17 & 5 & 2 & 1 & 1 & 1 & 2 & 118 & \\
\hline$\%$ & 4,2 & 71,1 & 14,4 & 4,2 & 1,6 & 0,8 & 0,8 & 0,8 & 1,6 & & \\
\hline
\end{tabular}

Tabla 7. Transectas Alrededores del $\mathrm{C}^{\circ}$ Cach Aike (Ea. Cach Aike).

\begin{tabular}{|c|c|c|c|c|c|}
\hline N Transectas & N muestreos & Superficie $\mathbf{~ m}^{2}$ & $\begin{array}{c}\text { N y \% muestreos } \\
\text { con hallazgos }\end{array}$ & $\begin{array}{c}\text { N artefactos / } \\
\text { densidades } \mathbf{m}^{2}\end{array}$ & \begin{tabular}{l} 
Visibilidad \\
\hline 12
\end{tabular} \\
\hline 213 & 257.500 & $14(3,75 \%)$ & 0,00005 & Muy buena \\
\hline
\end{tabular}


Tabla 8: Transectas Alrededores del $\mathrm{C}^{\circ}$ Cach Aike (Ea Cach Aike). Frecuencias y porcentajes de clases artefactuales por materia prima. Referencias: DTE: desecho de talla externo, DTI: desecho de talla interno, Nu: Núcleo, Rp: Raspador y Ch: Chunk.

\begin{tabular}{|c|c|c|c|c|c|c|c|}
\hline \multirow{3}{*}{ Materias primas } & \multirow{2}{*}{\multicolumn{5}{|c|}{ Artefactos }} & \multirow[b]{3}{*}{ Totales } & \multirow[b]{3}{*}{$\%$} \\
\hline & & & & & & & \\
\hline & DTE & DTI & $\mathrm{Nu}$ & $\mathrm{Rp}$ & $\mathrm{Ch}$ & & \\
\hline Basalto & 1 & 0 & 0 & 0 & 0 & 1 & 7,1 \\
\hline Calcedonia & 0 & 0 & 0 & 0 & 1 & 1 & 7,1 \\
\hline Limolita & 0 & 1 & 1 & 0 & 0 & 2 & 14,2 \\
\hline Lutita & 0 & 2 & 0 & 0 & 0 & 2 & 14,2 \\
\hline Obsidiana & 0 & 1 & 0 & 0 & 0 & 1 & 7,1 \\
\hline Sílice & 0 & 4 & 0 & 1 & 0 & 5 & 35,7 \\
\hline Toba & 0 & 2 & 0 & 0 & 0 & 2 & 14,2 \\
\hline Totales & 1 & 10 & 1 & 1 & 1 & 14 & \\
\hline$\%$ & 7,1 & 71,4 & 7,1 & 7,1 & 7,1 & & \\
\hline
\end{tabular}

silicificada verde. No se registraron restos faunísticos. Por último, cabe mencionar que en la margen oeste del lago Tar no se realizaron hallazgos (Tabla 1) lo que, junto con las bajas frecuencias/densidades de la margen norte, contrasta aún más con las frecuencias registradas en la margen este. Así, se destaca su mayor intensidad de uso por parte de las poblaciones cazadoras recolectoras durante el Holoceno.

\section{2- Alrededores del cerro Cach Aike}

El cerro Cach Aike es un cuello volcánico (neck) que se destaca por su ubicación central en la cuenca baja de los lagos Tar y San Martín. Se plantearon transectas que evaluaron espacios del área inmediatamente al oeste del cerro, en campos de la Ea. Cach Aike. Aunque la visibilidad arqueológica es muy buena, se observó una muy baja frecuencia artefactual y el empleo de las mismas materias primas descriptas para la región (Tablas 7 y 8). A diferencia de lo registrado en la colección Thierauf (Espinosa et al. 2007), las densidades artefactuales registradas en las transectas son muy bajas (Tablas 7 y 8 ).

Por otra parte se exploraron, también de manera dirigida, los alrededores del cerro Cach Aike, en busca de entierros humanos. Sobre el borde oeste de una pequeña elevación, a aproximadamente $5 \mathrm{~km}$ en dirección NO respecto del cerro Cach Aike, se registró una estructura tipo chenque (Chenque 1). La misma estaba construída con lajas y rocas tabulares localmente disponibles con escasa sedimentación en su interior y el crecimiento de arbustos en su mitad este. Sus dimensiones son 3,30 m en el eje E-O y 3,30 m en el eje N-S. Se recuperó un único esqueleto humano, con un alto grado de articulación y depositado en posición dorsal extendida, conformando un entierro primario sin asociación con artefactos. El cráneo, parte de la columna vertebral, el húmero y el cúbito izquierdo se encontraban fuera de su posición anatómica, indicando modificación postdepositacional. La mayor parte de las vértebras y costillas, así como la escápula izquierda, habían desaparecido, posiblemente afectadas por el mismo proceso. Los huesos desplazados presentaban evidencias de meteorización. El esqueleto apoyaba sobre una fina capa de sedimento depositado sobre las rocas de base, que conformaban una superficie aproximadamente plana. Los restos corresponden a un individuo adulto, cuyo cráneo y huesos largos poseen una morfología robusta a muy robusta, por lo que su sexo es probablemente masculino. Esta determinación se sustenta también en las dimensiones de la cabeza femoral y humeral, únicos indicadores sexuales cuantificables debido al mal estado de conservación de la pelvis. La edad probable al momento de morir se situaría entre los 30 y los 45 años, estimada sobre la base del grado de cierre de las suturas craneanas. Otros indicadores que apoyan esta estimación fueron la ausencia de alteraciones articulares (v.g. osteofitosis, artrosis) en la mayoría de las superficies articulares y el moderado grado de desgaste observado en los segundos y terceros molares. Numerosas unidades anatómicas, particularmente aquellas desplazadas de su posición original (v.g. calvaria, mandíbula, húmero y cúbito izquierdos), se encuentran meteorizadas con una alta frecuencia de grados 2 y 3 (sensu Behrensmeyer 1978). La superficie de los huesos presenta abundantes marcas de raíces y numerosos sitios de depositación de dióxido de manganeso. En algunos casos, hay evidencias de ataque químico, lo que generó la consecuente remoción extensiva del área cortical. Desde un punto de vista paleopatoló- 


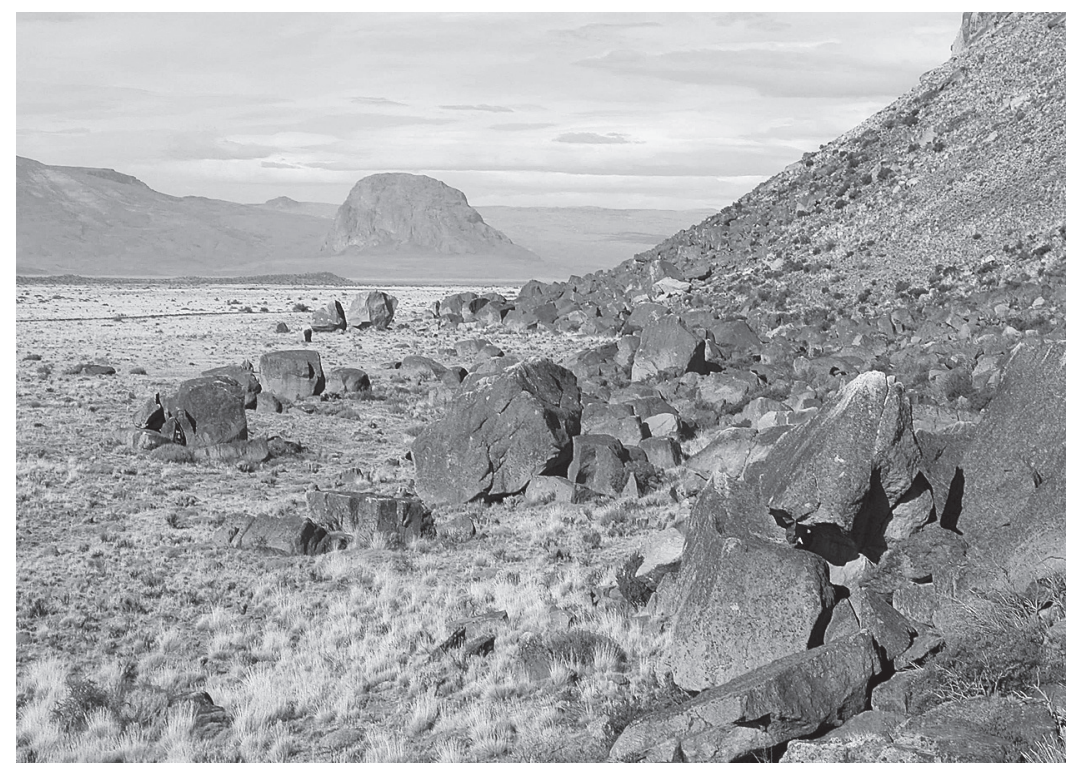

Fig. 3. Campo de Bloques 1. En el centro de la imagen se destaca el Bloque 1.

gico, se detectó un mínimo de 2 líneas de hipoplasia del esmalte dental, localizadas en los caninos inferior y superior izquierdos, no observándose caries ni lesiones periodontales. Aproximadamente un tercio de las piezas dentales presentaba fracturas de carácter tafonómico. El cráneo no mostraba evidencias de hiperostosis porótica. Se halló una alteración articular a nivel de uno de los cóndilos del occipital, con su correlato en el atlas. Una de las tibias presenta evidencias de inflamación, con una leve reacción subperióstica. Una muestra de colágeno obtenida sobre el quinto metatarsiano de este esqueleto fue fechada en $1.000 \pm 40$ años AP (UGAMS 1690) Los valores isotópicos indican una dieta terrestre, altamente proteica $\left(\delta^{13} \mathrm{C}=-18,3 \%\right.$; $\delta^{15} \mathrm{~N}=12,42 \%$ ).

\section{3- Margen sur del lago San Martín}

Los trabajos se iniciaron en el extremo sureste del lago San Martín hasta alcanzar, hacia el oeste, la península Maipú, que se ubica inmediatamente por debajo de la línea de dispersión del bosque actual. Con fines operativos -y a los efectos de ordenar la información arqueológica- se dividió a la margen sur en tres sectores en función de las cotas. Así, se consideró como sectores bajos -que conforman el fondo de cuenca- a los comprendidos entre los 270

Tabla 9. Transectas en los distintos sectores de la margen sur del lago San Martín.

\begin{tabular}{|c|c|c|c|c|c|}
\hline N Transectas & $\mathrm{N}$ muestreos & Superficie $\mathrm{m}^{2}$ & $\begin{array}{c}\mathrm{N} \text { y } \% \text { muestreos } \\
\text { con hallazgos }\end{array}$ & $\begin{array}{l}\mathrm{N} \text { artefactos / } \\
\text { densidades } \mathrm{m}^{2}\end{array}$ & Visibilidad \\
\hline \multicolumn{6}{|c|}{ Sectores bajos (270-400 m.s.n.m) } \\
\hline 19 & 264 & 287.200 & $7(2,65 \%)$ & $\begin{array}{c}10 / \\
0,00003\end{array}$ & Buena - Muy buena \\
\hline \multicolumn{6}{|c|}{ Península Maipú (300 m s.n.m.) } \\
\hline & & \multicolumn{2}{|c|}{$240.000 \mathrm{~m}^{2}$} & $\begin{array}{c}1 / \\
0,000004\end{array}$ & \\
\hline & & \multicolumn{2}{|c|}{$65.720 \mathrm{~m}^{2}$} & $\begin{array}{l}535 / \\
0,008\end{array}$ & \\
\hline \multicolumn{6}{|c|}{ Sectores intermedios (400 -700 m.s.n.m.) } \\
\hline 3 & 27 & 40.500 & $2(7,40 \%)$ & $\begin{array}{c}2 / \\
0,00004 \\
\end{array}$ & Mala - Regular \\
\hline \multicolumn{6}{|c|}{ Sectores altos ( $\geq 700$ - m.s.n.m.) } \\
\hline 5 & 60 & 60.500 & 0 & 0 & Mala - Regular \\
\hline
\end{tabular}


Tabla 10. Transectas en los sectores bajos de la margen sur del lago San Martín.

Referencias: Toba sil v: Toba silicificada verde, DTI: desecho de talla interno, Nu: Núcleo, Rp: Raspador y Per: Percutor.

\begin{tabular}{|c|c|c|c|c|c|c|c|}
\hline \multirow[b]{2}{*}{ Materias primas } & \multicolumn{5}{|c|}{ Artefactos } & \multirow[b]{2}{*}{ Totales } & \multirow[b]{2}{*}{$\%$} \\
\hline & DTI & $\mathrm{Nu}$ & $\mathrm{Rp}$ & Bo & Per & & \\
\hline Basalto & 0 & 1 & 0 & 0 & 0 & 1 & 10 \\
\hline Gabro & 0 & 0 & 0 & 1 & 0 & 1 & 10 \\
\hline Granito & 1 & 0 & 0 & 0 & 1 & 2 & 10 \\
\hline Obsidiana & 2 & 1 & 1 & 0 & 0 & 4 & 40 \\
\hline Toba sil.v & 2 & 0 & 0 & 0 & 0 & 2 & 20 \\
\hline Totales & 5 & 2 & 1 & 1 & 1 & 10 & \\
\hline$\%$ & 50 & 20 & 10 & 10 & 10 & & \\
\hline
\end{tabular}

y los $400 \mathrm{msnm}$, caracterizados por un ambiente de estepa, en la que predominan especies arbustivas y herbáceas. En este espacio y, sobre la margen sudeste del lago, hay un campo de grandes bloques -producto de la remoción en masa y de movimientos gravitacionales- que se extiende a lo largo de 1400 metros en sentido este-oeste. Fue denominado Campo de Bloques 1 (Fig. 3). Por último, y también dentro de los sectores bajos, se incluyó al istmo de la península Maipú, que se ubica en el borde del bosque.

Se consideraron como sectores intermedios a los espacios ubicados entre los 400 y los $700 \mathrm{msnm}$ en un ambiente de estepa graminosa (Bamonte 2008). Aquí también se localiza otro campo de bloques (Campo de Bloques 2), inmediatamente al suroeste del anterior pero de sólo $400 \mathrm{~m}$ de extensión. Ambos campos de bloques presentan la mayor oferta de reparos rocosos de la región en estudio y muestran evidencias de utilización humana a lo largo del tiempo.

Por sectores altos se tomaron aquellos espacios localizados por encima de los $700 \mathrm{msnm}$, donde también predomina la estepa graminosa. Sobre la base de estas consideraciones se describen, a partir del sureste del lago, los trabajos y hallazgos realizados. Mientras que, en la Tabla 9 se detalla la información distribucional recuperada en cada uno de estos sectores.
En el Campo de Bloques 1 se registraron ocho bloques con reparo y con materiales líticos en superficie, todos con sedimentos potencialmente excavables. Al relevar los espacios interbloques se registró un biface de basalto y siete desechos internos de obsidiana y dos de sílice.

En las transectas llevadas a cabo sobre la cota de $354 \mathrm{~m}$ sólo se recuperaron 10 artefactos. Uno de ellos es un hallazgo aislado y corresponde a una lasca angular de obsidiana. El resto forma una concentración ubicada sobre la margen noreste de una laguna temporal, denominada Laguna Quemada, con excelente visibilidad arqueológica producto de un incendio reciente (Tabla 10). Por su parte, en las transectas llevadas a cabo en las pampas que se localizan debajo del Campo de Bloques 2 no se produjeron hallazgos. No obstante, fuera de ellas y, a lo largo de nueve metros sobre un camino de ovejas, se registró un evento de talla en lutita (un AFS; cuatro desechos internos y dos externos). Además, se realizaron observaciones puntuales en espacios con buena y muy buena visibilidad arqueológica entre el Campo de Bloques 2 y la península Maipú (Tabla 11). Las mismas permiten afirmar que aún cuando los hallazgos se vinculan directamente con condiciones de buena visibilidad arqueológica las frecuencias artefactuales son muy bajas; hecho éste

Tabla 11. Otros espacios relevados en los sectores bajos.

\begin{tabular}{|l|l|}
\hline \multicolumn{1}{|c|}{ Lugar } & \multicolumn{1}{|c|}{ N y tipo artefactual y materia prima } \\
\hline Morro sobre la margen derecha arroyo Macías. & $\mathrm{N}=2 ;$ un fragmento bifaz y un desecho de talla ambos en sílice. \\
\hline Ruta provincial № 33, sobre un médano. & $\mathrm{N}=2$; un raspador y un desecho de talla ambos en sílice \\
\hline Sobre un camino interno de la Ea. El Castillo. & $\begin{array}{l}\mathrm{N}=4 ; \text { un núcleo y un desecho de talla en toba y dos desechos } \\
\text { de talla en lutita. }\end{array}$ \\
\hline $\begin{array}{l}\text { Margen derecha de la desembocadura del río Elena, sobre una } \\
\text { acumulación eólica. }\end{array}$ & $\begin{array}{l}\mathrm{N}=2 ; \text { una punta de proyectil de basalto y un fragmento de bifaz } \\
\text { en toba silicificada verde. }\end{array}$ \\
\hline $\begin{array}{l}\text { Ea. El Castillo, sobre un médano utilizado como cantera de } \\
\text { extracción de áridos. }\end{array}$ & $\begin{array}{l}\mathrm{N}=4 ; \text { un fragmento de núcleo en lutita; un raspador en calcedonia } \\
\text { un desecho en dacita y uno en madera silicificada. }\end{array}$ \\
\hline
\end{tabular}


Tabla 12. Dataciones radiocarbónicas (sin calibrar) y valores isotópicos para el Bloque 1- Oquedad y Alero La Angelita 1. Referencias: C. Cuadrícula.

\begin{tabular}{|l|l|c|c|c|c|}
\hline \multicolumn{5}{|c|}{ Margen Sureste del lago San Martín (Sectores bajos). Campo de Bloques 1. Bloque $\mathbf{1}$} \\
\hline \multicolumn{1}{|c|}{ Sitio, cuadrícula y nivel } & Elemento datado (Lama guanicoe) & Datación & $\delta^{13} \mathbf{C}$ & $\delta^{15} \mathbf{N}$ & Laboratorio \\
\hline $\begin{array}{l}\text { Oquedad. C1. } \\
74-79 \mathrm{~cm}\end{array}$ & Tibia (fragmento de diáfisis). & $1.030 \pm 50$ & $-19,77$ & 4,93 & UGAMS 1500 \\
\hline $\begin{array}{l}\text { Oquedad. C1. } \\
39 \mathrm{~cm}\end{array}$ & $\begin{array}{l}\text { Vértebra toráxica (huellas de } \\
\text { corte en proceso espinoso) }\end{array}$ & $1.040 \pm 50$ & $-20,09$ & 6,59 & UGAMS 1448 \\
\hline $\begin{array}{l}\text { Oquedad. C2. } \\
117 \mathrm{~cm}\end{array}$ & Húmero distal (marcado perimetral) & $1.980 \pm 40$ & $-19,7$ & 5,8 & UGAMS 2228 \\
\hline $\begin{array}{l}\text { Oquedad. C1. } \\
127,5 \mathrm{~cm}\end{array}$ & $\begin{array}{l}\text { Vértebra toráxica (huellas de } \\
\text { corte en proceso espinoso) }\end{array}$ & $2.270 \pm 50$ & $-19,93$ & 6,36 & UGAMS 1449 \\
\hline $\begin{array}{l}\text { Alero } \\
95 \mathrm{~cm}\end{array}$ & Escápula & $3.140 \pm 40$ & $-19,65$ & 6,47 & UGAMS 1691 \\
\hline $\begin{array}{l}\text { Oquedad. C2. } \\
127 \mathrm{~cm}\end{array}$ & Metacarpo & $3.770 \pm 50$ & $-19,4$ & 6,7 & UGAMS 2229 \\
\hline $\begin{array}{l}\text { Oquedad. C1. } \\
150 \mathrm{~cm}\end{array}$ & Tibia (fragmento de diáfisis). & $9.760 \pm 60$ & $-19,16$ & 6,20 & UGAMS 1368 \\
\hline
\end{tabular}

que se ve reforzado por la ausencia de artefactos en espacios con muy buena visibilidad tales como en la Laguna Quemada, una pista de aterrizaje y líneas sismográficas.

La información estratigráfica de los sectores bajos proviene del Campo de Bloques 1, de sondeos llevados a cabo en torno al sitio denominado Bloque 1-Oquedad -que es un gran bloque partido-, tanto en una pequeña oquedad como en un alero lindante. En el Bloque 1-Oquedad (con una superficie de 10,5 $\mathrm{m} \times 2,8 \mathrm{~m}$ ) se excavaron $2 \mathrm{~m}^{2}$, siguiendo niveles artificiales de cinco $\mathrm{cm}$, y en el alero $1 \mathrm{~m}^{2}$. Hasta el momento, se analizaron los materiales de la cuadrícula 1 de la Oquedad y sólo se emplearon materiales de la cuadrícula 2 y del alero para completar el marco cronológico del sitio.

Las ocupaciones se inician alrededor de 9700 años AP, continuando hasta al menos 1000 años AP. (Tabla 12). El primer nivel de ocupación apoya sobre el till y se encuentra cubierto por un nivel de rocas. Por sobre este nivel ya todas las dataciones son menores a 3700 años, lo que indica la posible existencia de un hiato de 6000 años radiocarbónicos, $y$, en el caso de los fechados más tardíos, puede verse que son similares pese a la diferencia estratigráfica de $40 \mathrm{~cm}$. Esto alertaría acerca de procesos de mezcla de materiales arqueológicos, posiblemente relacionados con la actividad de roedores.

En la cuadrícula 1 se recuperó un total de 2353 artefactos líticos, de los cuales 1352 corresponden a desechos de talla con talón, núcleos y artefactos formatizados (Pallo 2008, Tabla 1). Se reconocieron
14 clases artefactuales, con una alta proporción de desechos de talla (96\%) en relación con los núcleos (1\%) y los artefactos formatizados (3\%). La riqueza artefactual se mantiene estable a lo largo de toda la secuencia. El 75\% de los artefactos formatizados posee algún tipo de fractura, siendo mayoría los raspadores (44,73\%), seguidos por los artefactos de formatización sumaria $(26,31 \%)$ y las raederas (7,89\%). Un alto porcentaje se encuentra agotado, por lo cual han sido descartados por fractura $y / 0$ embotamiento de los filos.

Para la manufactura de los artefactos se han empleado 17 clases de rocas. Predomina la obsidiana $(34,7 \%)$, la dacita $(31,5 \%)$ y las sílices $(21,4 \%)$. Con respecto a los núcleos, son mayoritarios los de dacita (65\%), que se presentan en tamaños medianos a grandes, están enteros y algunos poseen potencial de reactivación. Mientras que, los de obsidiana (30\%) son de tamaño pequeño a mediano, están fracturados y sin potencial de reactivación. Están ausentes los núcleos de sílice (Pallo 2008). Si bien las materias primas empleadas en los artefactos formatizados son las mismas que se observan entre los desechos de talla, existen valores discordantes entre ellos que sugieren que las primeras etapas del proceso de talla se realizaron fuera del sitio. Por otra parte, la amplia distribución de los desechos de tamaño muy pequeño y pequeño y la presencia en algunos niveles del 17\% de lascas de reactivación indirecta apoya la inferencia acerca de la presencia de las instancias finales de formatización y mantenimiento de filos (Pallo 2008, 2009). La variedad y aprovechamiento 
Tabla 13. Dataciones radiocarbónicas (sin calibrar) y valores isotópicos para los Bloques 1 y 2 del Campo de Bloques 2.

\begin{tabular}{|l|l|c|c|c|c|}
\hline \multicolumn{5}{|c|}{$\begin{array}{c}\text { Margen Sureste del lago San Martín (Sectores intermedios). } \\
\text { Campo de Bloques 2. Bloques 1 y 2 }\end{array}$} \\
\hline \multicolumn{1}{|c|}{$\begin{array}{c}\text { Elemento datado } \\
\text { (Lama guanicoe) }\end{array}$} & Datación & $\delta^{13}$ C & $\delta^{15}$ N & Laboratorio \\
\hline Bloque 1. $(-60 \mathrm{~cm})$ & Escápula & $3.000 \pm 50$ & $-20,0$ & 9,7 & UGAMS 1969 \\
\hline Bloque 2. $(-78 \mathrm{~cm})$ & $\begin{array}{l}\text { Vértebra cervical (huellas de corte en } \\
\text { proceso) }\end{array}$ & $4.720 \pm 50$ & $-20,2$ & 6,5 & UGAMS 1970 \\
\hline
\end{tabular}

de las materias primas locales dan cuenta del fácil acceso y la disponibilidad local de rocas.

Por otra parte, se destaca que el uso de la obsidiana aumenta a lo largo del tiempo y se vuelve dominante en los momentos más tardíos de la ocupación. Esto sugiere que la incorporación de la margen sudeste del lago San Martín a los rangos de acción de las poblaciones humanas estaría vinculado con áreas situadas al norte y al este, o en relación con ellas (Belardi et al. 2007). El aprovechamiento de la obsidiana debió implicar un mayor grado de inversión de trabajo que con las rocas locales, lo que se refleja en las menores dimensiones del conjunto artefactual y la presencia de núcleos. En contraposición, el rango amplio de dimensiones que abarcan los artefactos manufacturados en dacita, sumado al estado de los núcleos y a los escasos artefactos formatizados en rocas locales, podría ser atribuido a la alta disponibilidad y accesibilidad de los recursos líticos en el área (Espinosa et al. 2007).

Con respecto a la arqueofauna, predomina el guanaco a lo largo de toda la secuencia, con un NISP de 117. Se encuentran representados elementos de todas las regiones anatómicas (ver Stiner 1991). Sólo se registró un elemento de choique. Los valores de $\mathrm{pH}$ en pasta oscilan entre 5,6 y 6,5, -ligeramente ácido- lo que es coincidente con el buen grado de preservación de los restos. El 67,3 \% se encuentra en el estadio 1 de meteorización y el 32,6 en el estadio 2 (Behrensmeyer 1981).

Por detrás de la oquedad, sobre el lado sur del bloque, se registró un motivo pintado correspondiente a un negativo de mano izquierda en rojo. Este ha sido el único motivo rupestre registrado en el espacio de fondo de cuenca desde la margen este del lago Tar hacia el oeste.

Las características tecnológicas mencionadas indican la realización de un abanico limitado de tareas asociadas a la reducción de núcleos en dacita y obsidiana y, principalmente, a las últimas etapas del proceso de manufactura lítica, incluido el transporte y descarte de artefactos. Sumado a ello, la diversidad artefactual hallada sugiere el equipamiento de individuos (Kuhn 1995) y el uso logístico del sitio Bloque 1-Oquedad por grupos vinculados con espacios ubicados hacia el este de la cuenca. Este resultado es complementario con el patrón de uso residencial asociado a los sitios de superficie de Cach Aike para el Holoceno tardío (Espinosa et al. 2007). La ocupación temprana del sitio se relacionaría con la exploración de nuevos espacios (Borrero 1989-1990; Borrero y Franco 1997). El resto de la secuencia indica tanto una relativa continuidad en la ocupación, como una baja intensidad en el uso del sitio. Asimismo, la secuencia artefactual y arqueofaunística sugiere una relativa estabilidad en el tipo de actividades desarrolladas a lo largo del tiempo.

En los Sectores intermedios se realizaron excavaciones en el denominado Campo de Bloques 2 (518 msnm) (Fig. 1), que tiene una extensión aproximada de $400 \mathrm{~m}$ sobre un eje este-oeste y se encuentra sobre una terraza glaciaria, dominando una extensa pampa y un mallín. Los bloques apoyan sobre un nivel de terraza que desciende hasta el lago San Martín. Se registraron cuatro bloques que ofrecían reparos y materiales líticos en superficie. Los trabajos de excavación se centralizaron en los denominados Bloques 1 y 2 (Belardi y Campan 2009). Las ocupaciones humanas se habrían iniciado hacia 4700 años AP. y apoyan sobre el till (Tabla 13).

El primero de ellos es un alero orientado al sudoeste, con una superficie de aproximadamente $14 \mathrm{~m}^{2}$ y una pendiente de $6^{\circ}$ que desciende hacia el norte. Se excavó una cuadrícula de $1 \mathrm{~m}^{2}$, considerando niveles artificiales de $5 \mathrm{~cm}$. Se recuperó un total de 293 artefactos líticos (todos desechos de talla y núcleos), de los cuales 133 tiene talón. Se emplearon sílices (20\%), lutitas (19\%), tobas (15,4\%) -sobre la cual se realizaron también los núcleos-, dacitas $(14,7 \%) y$, en menor proporción, obsidiana (10,3\%). Estas rocas son de muy buena y excelente calidad 
para la talla y se distribuyen de manera homogénea a lo largo de toda la secuencia. La arqueofauna está representada principalmente por guanaco, que se encuentra presente a lo largo de toda la secuencia y con una variada representación de partes esqueletarias (NISP=31). En líneas generales, el estado de conservación de los restos óseos es relativamente bueno ( $\mathrm{pH}$ en pasta 6,84); sobre los que se pudo determinar la meteorización, el 58\% se encuentra en estadio 2 y el 9, 6\% en estadio 3.

El Bloque 2 está formado por dos bloques contiguos, enfrentados y de gran tamaño, que generan un reparo de $8 \mathrm{~m}^{2}$. La pendiente es de $11^{\circ} \mathrm{y}$ desciende hacia el norte. Se excavó un metro cuadrado. Sólo se obtuvieron materiales arqueológicos en el bloque ubicado al norte. El total de artefactos líticos recuperados es 41 , de los cuales 32 son desechos de talla con talón. Además, hay un núcleo de toba, dos bolas sobre una materia prima indeterminada y un raspador y un fragmento de artefacto formatizado de sílice. Predomina el uso de la toba (50\%), seguido por el sílice (22,2\%), obsidiana (13,9\%), dacita $(8,3 \%)$ y hay un $5,5 \%$ de indeterminadas. En la arqueofauna también prevalece el guanaco; los restos corresponden a distintas regiones anatómicas $(\mathrm{NISP}=79)$ y hay un elemento de choique. Al igual que en el Bloque 1 la conservación de los restos es relativamente buena ( $\mathrm{pH}$ en pasta 7,91), con un $10,1 \%$ de ellos con meteorización en estadio 1 , $59,5 \%$ en estadio 2 y sólo un $2,5 \%$ en estadio 3 . En los elementos restantes la meteorización no se pudo determinar.

La ausencia de lascas de toba con corteza -materia prima de los tres núcleos recuperados en el Bloque 1- indicaría que los primeros estadios de reducción de esta roca se habrían realizado dentro de los mismos sitios pero en otros sectores, o que las formas base obtenidas, fueran transportadas a otros lugares. Los artefactos en sílice provenientes del Bloque 2 ya habrían ingresado manufacturados, al igual que las bolas. La existencia de núcleos abandonados, la mayoría con plataformas lisas y de lascas de mantenimiento y regularización de filos, son concordantes con actividades relacionadas con el aprovechamiento de rocas inmediatamente disponibles (Civalero y Franco 2003).

Las bajas frecuencias de artefactos y arqueofaunas recuperadas sugieren que los grupos cazadores-recolectores emplearon los Bloques 1 y 2 en forma esporádica y transitoria. A la vez, la presencia de obsidiana indicaría el acceso a los bloques desde el este. De esta forma, puede sostenerse el uso logístico del Campo de Bloques 2. Este escenario es concordante con la obtención y transporte de formas base desde los bloques hacia otros espacios, como así también en el acceso a ellos de individuos ya equipados.

Entonces, puede verse que la evidencia recuperada en ambos campos de bloques, si bien el caso del Bloque 1-Oquedad indica una mayor profundidad temporal e intensidad de uso del Campo de Bloques 1 , permite considerar que las poblaciones humanas utilizaron el sector sudeste del lago San Martín de forma redundante y sobre una base logística.

Además de las excavaciones recién mencionadas, se llevaron a cabo transectas en las cotas de 500 y 550 metros y, tal como indica la Tabla 9, se recuperaron sólo dos artefactos: un núcleo de toba

Tabla 14. Peladal sectores intermedios. Frecuencias y porcentajes de clases artefactuales por materia prima. Referencias: Madera sil.: Madera silicificada, Toba sil. v.: toba silicificada verde, DTE: desecho de talla externo, DTI: desecho de talla interno, Nu: núcleo y Rp: raspador.

\begin{tabular}{|c|c|c|c|c|c|c|}
\hline \multirow[b]{2}{*}{ Materias primas } & \multicolumn{4}{|c|}{ Artefactos } & \multirow[b]{2}{*}{ Totales } & \multirow[b]{2}{*}{$\%$} \\
\hline & DTE & DTI & $\mathrm{Nu}$ & $\mathrm{Rp}$ & & \\
\hline Basalto & 0 & 4 & 0 & 0 & 4 & 8 \\
\hline Calcedonia & 0 & 1 & 0 & 0 & 1 & 2 \\
\hline Limolita & 0 & 1 & 1 & 1 & 3 & 6 \\
\hline Madera sil & 0 & 4 & 0 & 0 & 4 & 8 \\
\hline Obsidiana & 3 & 5 & 0 & 0 & 8 & 16 \\
\hline Sílice & 0 & 11 & 2 & 6 & 19 & 38 \\
\hline Toba & 0 & 7 & 1 & 0 & 8 & 16 \\
\hline Toba sil. v. & 0 & 3 & 0 & 0 & 3 & 6 \\
\hline Totales & 3 & 36 & 4 & 7 & 50 & \\
\hline$\%$ & 6 & 72 & 8 & 14 & & \\
\hline
\end{tabular}


y una lasca de sílice. También sobre una pampa, se recolectó una concentración de artefactos que se encontraba distribuida sobre una superficie de $656 \mathrm{~m}^{2}$ (Tabla 14). Tanto las materias primas como su representación proporcional y los tipos artefactuales presentes son similares a los registrados en los campos de bloques.

El último espacio relevado dentro de los sectores bajos fue la península Maipú. Allí se recorrieron tanto el interior como el istmo (Tabla 9 y Fig. 1) (Espinosa et al. 2009). Este último se encuentra enmarcado por médanos en el este, una albúfera en el oeste y su interior presenta numerosas lagunas. La península tiene un relieve muy quebrado, con la presencia de bosque tanto extendido como en mosaico. Se plantearon transectas dirigidas y no dirigidas en zonas con muy buena visibilidad arqueológica: los médanos y las lagunas del istmo.

Como resultado de la implementación de las transectas, se recolectó un total de 536 desechos con talón, núcleos y artefactos formatizados, todos en superficie y a cielo abierto (Espinosa et al. 2009). Las mayores frecuencias se vinculan con las lagunas y los médanos. En las primeras se observan altas frecuencias de materiales ( $\mathrm{N}=304)$ que muestran la utilización de 11 tipos de rocas diferentes, como así también, el aprovechamiento expeditivo de aquellas disponibles localmente, como la toba silicificada verde que es de muy buena calidad para la talla. La mayoría de los núcleos y desechos de talla son de esta materia prima (49,6\%), así como un cepillo, posiblemente vinculado con el procesamiento de la madera. Las tareas desarrolladas por los grupos humanos se relacionarían con el aprovisionamiento de la materia prima local y la realización de las primeras etapas de manufactura de artefactos procurando la obtención de formas base.

Por su parte, en los médanos se recuperó un total de 80 artefactos, en su mayoría núcleos $(\mathrm{N}=18)$, seguido por molinos $(\mathrm{N}=17)$, raspadores $(\mathrm{N}=6)$ y percutores $(\mathrm{N}=5)$, todos manufacturados en materias primas disponibles localmente. También es interesante señalar que la representación de la obsidiana alcanza el 10\% de la muestra. Este porcentaje resulta aún más significativo en virtud de la distancia a la fuente de origen. Este sector evidencia ser un espacio equipado y con mayor diversidad artefactual y materias primas utilizadas. La presencia de las clases artefactuales mencionadas permite vincularlo con la realización de actividades de procesamiento de recursos de subsistencia, entre las cuales puede señalarse la manufactura de artefactos bifaciales. Por su parte, las menores frecuencias artefactuales se distribuyen en el interior de la península, en la planicie del istmo y en el sector oeste del istmo de la península Maipú (Espinosa et al. 2009).

Si se considera a la península Maipú en su totalidad, el istmo es el extremo ubicado más al oeste que pone en evidencia no sólo altas densidades artefactuales, sino también el registro de la mayor diversidad de clases y el empleo de toba silicificada verde, de amplia disponibilidad local. Asimismo, indicaría que el uso y la circulación de las poblaciones se focalizaron sobre el istmo y no hacia el interior de la península. En este sentido, al no haber diferencias en la disponibilidad de recursos básicos como el guanaco, agua y refugios, se ha propuesto que el istmo fue el sector más occidental y de más fácil acceso desde el este, lo que permitió utilizar logísticamente el interior de la península y el borde del bosque. De la misma manera, es el paso obligado hacia el oeste (ver Borrero y Muñoz 1999) y conforma un espacio protegido que permite controlar el ingreso de los guanacos a la península que, junto con el borde de bosque, son los lugares más occidentales en donde se los puede obtener. Debe destacarse que más allá del istmo no se registraron materiales arqueológicos.

Así, el registro arqueológico de la península Maipú es el resultado de una circulación pautada, en donde la disponibilidad de toba silicificada verde y su aprovechamiento reiterado produjo la acumulación de materiales en el sector de lagunas. En cuanto a los médanos, éstos fueron ocupados de manera similar a los sectores ubicados más hacia el este de la cuenca (Espinosa et al 2009).

La distribución espacial de los artefactos manufacturados en toba silicificada verde muestra un decrecimiento marcado hacia el este, alrededores del cerro Cach Aike y las márgenes este y sudeste del lago Tar. Este hecho estaría mostrando poco traslado de esta materia prima en esa dirección y/o su hallazgo eventual en relación con morenas que circundan los sectores bajos de la cuenca. En contraposición, hacia el este es mayor el descarte de la obsidiana evidenciando un uso más intenso de la misma. Esto es concordante con la utilización 


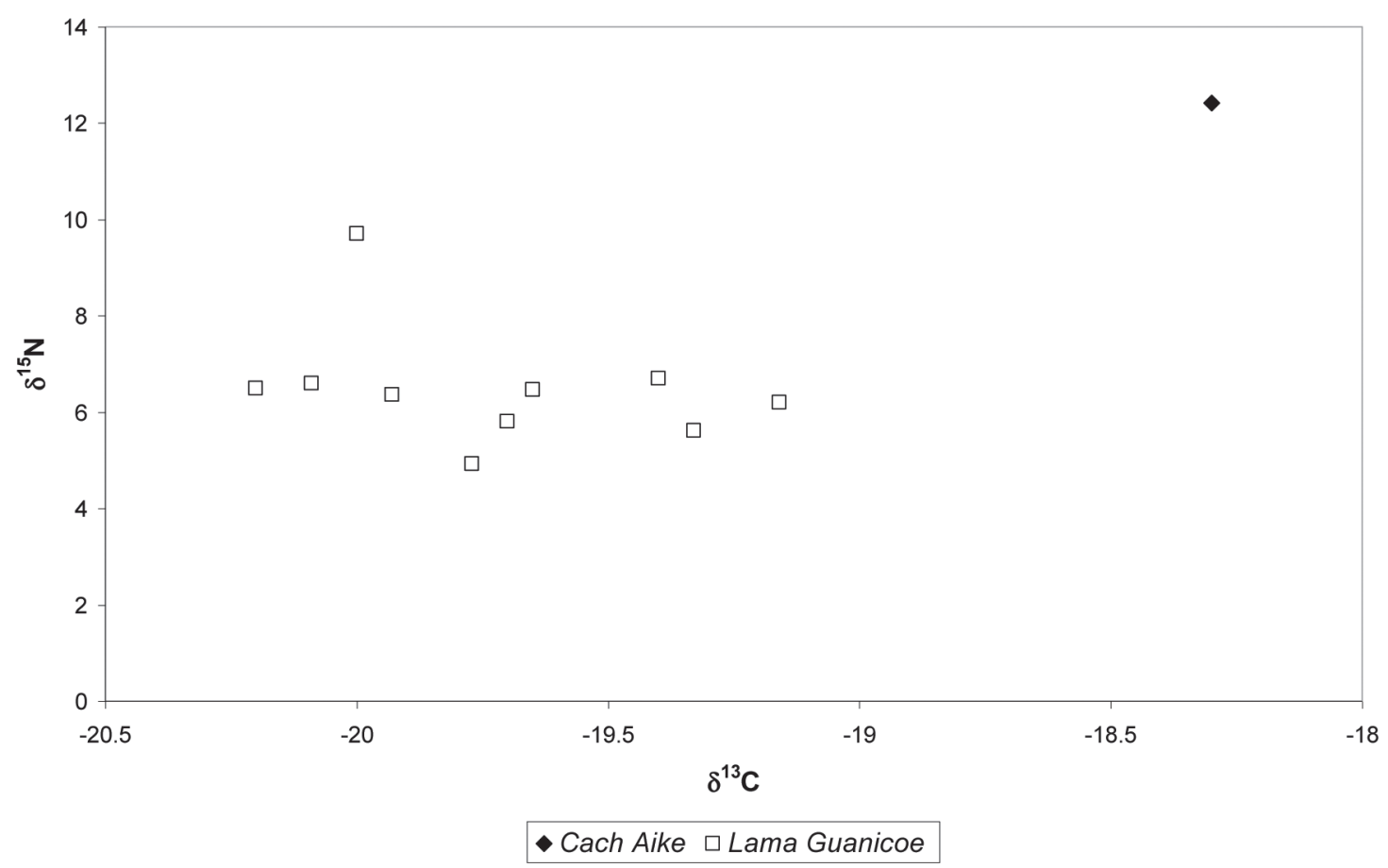

Fig. 4. Valores isotópicos de restos arqueofaunísiticos (guanaco) y humano.

planificada de los espacios occidentales y del equipamiento de individuos que conformarían grupos logísticos. En este sentido, el descarte de artefactos sin potencial de reactivación indica que el uso del istmo de la península Maipú y, por ende, el borde de bosque, no implicaría ningún riesgo en la explotación de los recursos existentes, ya que podrían ser obtenidos dentro de una circulación planificada. A la vez, la cercanía de la península a la cordillera permite postular su uso focalizado en primavera y verano (Espinosa et al 2009).

Por último, en los sectores altos la información distribucional -como resultado de las transectas dirigidas e implementadas en la cota 760- indica la ausencia de artefactos arqueológicos (Tabla 9). En parte, ello podría deberse a que la visibilidad oscila entre mala y regular. No obstante, por fuera de las transectas sólo se halló un núcleo de toba.

Los resultados alcanzados en la margen sur del lago San Martín sustentan diferencias en la intensidad del uso de esta cuenca por las poblaciones cazadoras-recolectoras al mostrar que las mayores densidades artefactuales se concentran en los campos de bloques y en torno al istmo de la península Maipú.

\section{INFORMACIÓN ISOTÓPICA REGIONAL}

La evaluación de los isótopos estables del $\delta^{13} \mathrm{C}$ y $\delta^{15} \mathrm{~N}$ ha demostrado ser un excelente marcador paleobiológico y paleoclimatológico (entre otros, Palmqvistq et al. 2003; Sponheimer et al. 2003). Así, se dio inicio a un estudio de la distribución natural de los isótopos estables en las cadenas tróficas de las cuencas de los lagos Tar y San Martín empleando las muestras arqueofaunísticas sobre las que se realizaban las dataciones radiocarbónicas.

Se presentan los resultados de colágenos de las 10 muestras de guanacos y del resto óseo humano de Cach Aike (Fig. 4). Para cada muestra se obtuvieron valores de $\delta^{13} \mathrm{C}, \delta^{15} \mathrm{~N}$ y un fechado directo por AMS. Los valores obtenidos tienen una media de $-19,72 \pm 0,34 \%$ o $\left(\delta^{13} \mathrm{C}\right)$ y $6,48 \pm 1,25 \%$ o $\left(\delta^{15} \mathrm{~N}\right)$.

En relación con los isótopos estables del C, los valores representan un grupo uniforme con muy poca dispersión; se encuentran ubicados dentro del rango de señales isotópicas registradas en estudios previos en el centro oeste de la provincia de Santa Cruz (Tessone et al. 2009). No obstante, estos valores están enriquecidos respecto de aquellos valores $\delta^{13} \mathrm{C}$ registrados en las arqueofaunas compiladas 
por Barberena y coautores (2009) pertenecientes a la región del Bosque de Patagonia Meridional, las que provienen de sitios arqueológicos del Parque Nacional Perito Moreno y Lago Argentino. Esta situación estaría reflejando el carácter estepario de las muestras de guanacos analizados.

Respecto del total, las muestras obtenidas significan un gran avance para el registro isotópico de Patagonia meridional, ya que sólo se contaba con tres determinaciones faunísticas para la provincia de Santa Cruz correspondientes a Lama guanicoe, Pterocnemia pennata y Chloephaga picta (Barberena 2002; Borrero et al. 2001) y cuatro pertenecientes a Lama guanicoe para toda Patagonia continental y Tierra del Fuego (Barberena et al. 2009). Así, los parámetros para realizar interpretaciones sobre este trazador se han modificado en aproximadamente 3\%o si consideramos las muestras de Santa Cruz (Barberena 2002; Borrero et al. 2001). Otros dos aspectos de las señales de nitrógeno de guanacos son importantes de resaltar. Por un lado, el amplio rango de distribución entre los valores mínimos y máximos (4,93\% y 9,70\%) y, por otro, el valor máximo produce un desplazamiento de los valores de las dietas de herbívoros en Patagonia meridional. Estas modificaciones señalan la relevancia de llevar a cabo un muestreo de carácter regional para el estudio de las variaciones isotópicas de los recursos cuando se llevan a cabo estudios paleodietarios de poblaciones humanas. El resto óseo humano recuperado en el Chenque 1 (alrededores del cerro Cach Aike) mostró una señal isotópica obtenida sobre colágeno de $\delta^{13} \mathrm{C}-18,27 \%$ y $\delta^{15} \mathrm{~N}$ $12,42 \%$. Para ilustrar esto, se graficaron dichos valores y los de los guanacos de los lagos Tar y San Martín. Considerando los fraccionamientos de cada trazador isotópico se puede plantear que el valor de los restos humanos del Chenque 1 refleja una dieta basada sobre recursos terrestres, que en el caso del $\delta^{13} \mathrm{C}$ son dietas correspondientes a la vía fotosintética $\mathrm{C}_{3}$, como es esperable para la región patagónica. Este valor se encuentran dentro del rango dietario obtenido en los restos óseos humanos del lago Salitroso con un $\delta^{13} \mathrm{C}(\mathrm{N}=24)=$ $-19,05 \pm 0,65 \%$ y $\delta^{15} \mathrm{~N}(\mathrm{~N}=11)=11,77 \pm 0,92 \%$ o (Tessone et al. 2009).

\section{DISCUSIÓN Y CONCLUSIONES}

Los primeros resultados arqueológicos obtenidos en la cuenca de los lagos Tar y San Martín permiten postular diferencias en el uso del espacio por parte de las poblaciones cazadoras recolectoras. La margen este del lago Tar presenta la mayor densidad y riqueza artefactual de la región, a lo que se suma la diversidad de rocas empleadas para la manufactura de artefactos, el registro de las primeras etapas del procesamiento del guanaco y la extracción de médula ósea. Por otra parte, su localización en el fondo de valle permite la ocupación a lo largo de todo el año y la articulación con las mesetas ubicadas al norte y al sur a través de los ríos Tar y Meseta. Así, la margen este del lago Tar habría actuado como concentradora de ocupaciones humanas, principalmente durante el Holoceno tardío, siendo utilizada de forma eminentemente residencial. Esta afirmación se ve reforzada al considerar que las otras márgenes, aún en el caso de la sureste, sólo han mostrado una muy baja señal arqueológica.

El uso humano más intenso del este de la región y del fondo de cuenca en general, se apoya no sólo en lo señalado para la margen este del lago Tar, sino también en las altas frecuencias de materiales arqueológicos registradas en los alrededores del cerro Cach Aike (Espinosa et al. 2007), incluyendo una estructura funeraria (Chenque 1). La presencia diferencial de entierros es vista como un indicador indirecto de la intensidad y continuidad del uso del espacio. Es en este segmento donde se espera una articulación mayor entre los sectores altos y bajos.

La señal arqueológica parece decaer en intensidad a medida que se avanza hacia el oeste. En la margen sureste del lago San Martín, la evidencia procedente de las excavaciones realizadas en los tres sitios -ubicados en los campos de bloques- $y$ focalizada sobre una baja intensidad de uso, la presencia de obsidiana y el equipamiento de individuos, sugiere un uso logístico de estos sectores (Belardi et al. 2007, 2009; Belardi y Campan 2009; Pallo 2008, 2009). No obstante, hay una mayor intensidad de ocupación del sitio Bloque 1-Oquedad con respecto a los bloques del Campo de Bloques 2 . Así, la incorporación al circuito de movilidad de los campos de bloques se habría llevado a cabo desde el este, por ejemplo desde los alrededores del cerro 
Cach Aike y la margen este del lago Tar. Al continuar desde los campos de bloques hacia el oeste la señal arqueológica continua decayendo, poniendo en evidencia una baja intensidad de uso humano. Lo señalado se ve reforzado aún más si se considera la escasa superficie que ofrece esta margen del lago. Entonces, es posible que no se haya producido una interacción significativa -durante los meses de verano- con los sectores altos.

Es recién en la península Maipú donde nuevamente se incrementa la señal arqueológica. Aquí, el registro recuperado es concordante con su uso logístico estacional y articulador de partidas hacia el sur y el oeste. A la vez se destaca el aprovechamiento de la toba silicificada verde, roca disponible localmente y de muy buena calidad para la talla (Espinosa et al. 2009). Por último, hacia los sectores ubicados más al oeste esta señal tiende a ser nula, tal como lo evidencia el relevamiento realizado en torno a la estancia Cóndor, donde no se recuperaron artefactos. Se ha postulado que las cuencas lacustres del oeste cordillerano -que forman callejones sin salida- serían marginales en virtud del uso discontinuo con respecto a los núcleos poblacionales localizados al este (Borrero 2004). En relación con ello, los espacios del oeste del San Martín habrían sido marginales con respecto a los del este, así el vector principal de circulación regional debió seguir esa dirección. Esta propuesta sostiene entonces la existencia de marcadas diferencias en la forma $e$ intensidad de uso del espacio entre la estepa y el bosque, aún cuando este último se hubiera extendido más allá de su límite actual.

Sobre la base de las discusiones precedentes es posible comenzar a integrar el poblamiento humano de las cuencas de los lagos Tar y San Martín con la ocupación de diferentes cuencas lacustres del oeste del extremo sur de Patagonia. En el caso bajo análisis el fechado más temprano corresponde al sitio Bloque 1-Oquedad, con 9.700 años A.P. Asimismo, dado que el registro arqueológico recuperado yace inmediatamente por encima del till, representaría la ocupación inicial de la región y se ajustaría a las expectativas del momento de exploración de un espacio (Borrero 1989-1990). Como se mencionara, la presencia de la obsidiana de Pampa del Asador permite proponer que la exploración del SE del lago San Martín se llevó a cabo por poblaciones procedentes del norte o del este.
La información generada es comparable con la obtenida hacia el norte en el sitio Cerro Casa de Piedra 7 (CCP7), localizado en el Parque Nacional Perito Moreno (NO de Santa Cruz) (Civalero y Aschero 2003) y con la disponible para el sitio Chorrillo Malo 2, ubicado en la margen sur del lago Argentino (Franco y Borrero 2003; Franco et al. 1999) (Fig. 5 en este trabajo y Figura 1 en Civalero y Franco 2003). Estas primeras ocupaciones también se ubican alrededor de ca. 9.700 años A.P. (ver Civalero y Franco 2003) y tienen en común el pertenecer a un mismo momento de exploración del sur de Patagonia. La evidencia polínica indica que antes del 7.540 años A.P. se desarrolló una estepa graminosa, posiblemente vinculada a condiciones más frías que en el resto de la secuencia. Este resultado sería correlacionable con otros registros polínicos del Holoceno temprano, como los recuperados en los sitios Cerro Casa de Piedra 7 y Chorrillo Malo 2 que evidencian el predominio de una estepa graminosa (Bamonte 2008). Durante este lapso la distribución de la obsidiana negra habría sido resultado de la existencia de rangos de circulación muy amplios de materias primas y poblaciones (Borrero 1994-1995; Civalero y Franco 2003). Por otra parte, estas primeras ocupaciones son más tardías que las registradas hacia el este, por ejemplo en la Meseta Central de Santa Cruz o las conocidas para la región de Pali Aike (ver Borrero y Manzi 2007).

En suma, estos espacios se ubican al oeste de otros que evidencian no sólo un poblamiento anterior, sino que muestran una mayor intensidad de uso que las cuencas de los lagos Tar y San Martín. Aquí, la evidencia sugiere un uso discontinuo a lo largo del tiempo, lo que también se ajusta -pero ahora en una escala suprarregional- a la propuesta de espacio marginal realizada por Borrero (2004).

El desarrollo de la cronología arqueológica y del marco paleoambiental permitirá establecer un marco adecuado para evaluar la interacción entre poblaciones humanas y ambientes. En este sentido, resulta interesante ver la ocupación de la región durante momentos vinculados con la Anomalía Climática Medieval (caso de la datación obtenida en el Chenque 1), lapso durante el cual no todos los espacios parecen haber estado ocupados, tal como lo propuesto para la región de lago Argentino (Borrero y Franco 2000). 


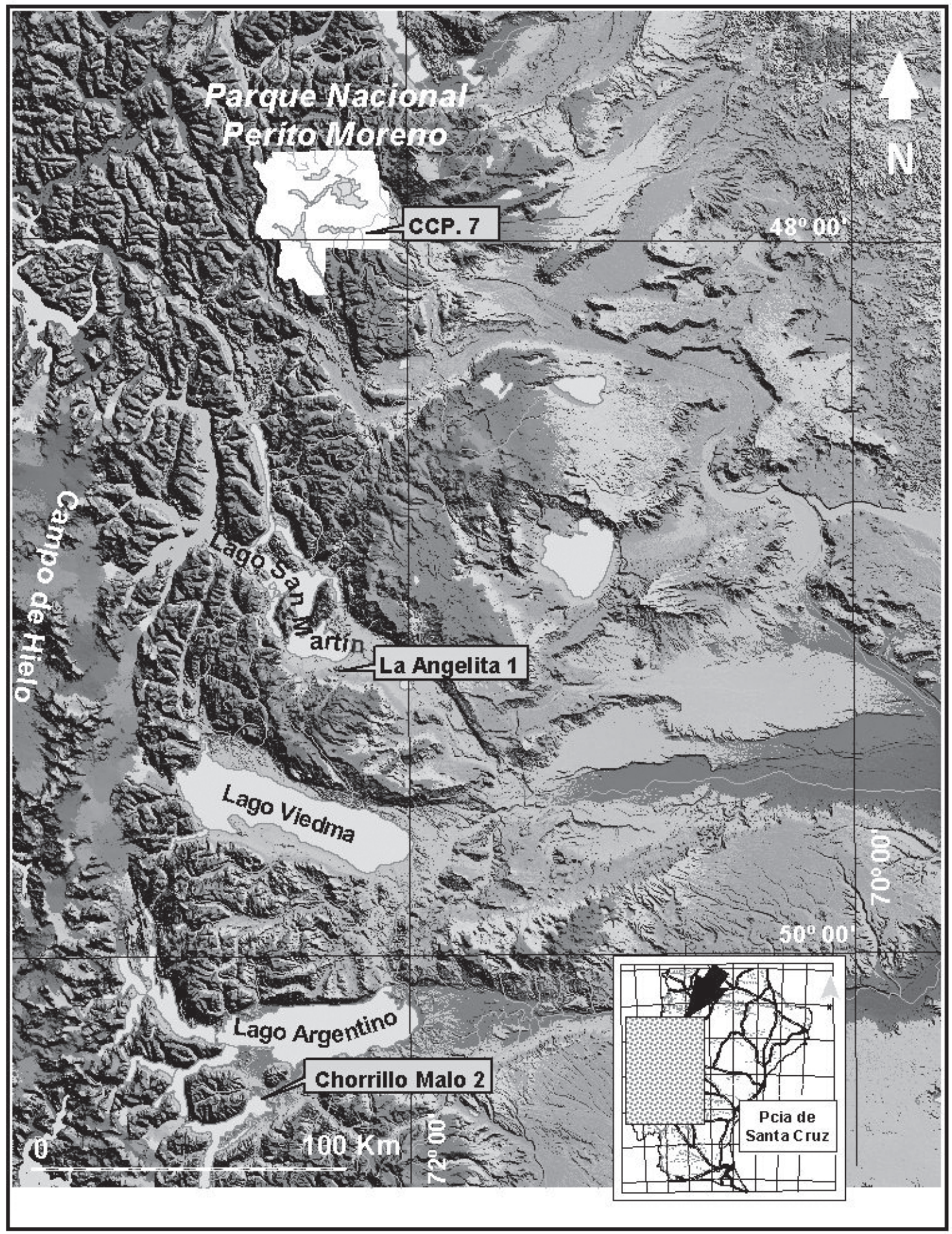

Fig. 5. Ubicación de sitios arqueológicos con fechados radiocarbónicos en torno a los 9700 años A.P. 
Por último, la realización de una ecología isotópica regional contribuye no sólo con la construcción de un marco de referencia para las cuencas bajo estudio sino para Patagonia meridional. Estos primeros resultados sistemáticos profundizan observaciones previas (Espinosa et al. 2007) y brindan un nuevo cuerpo de información a partir del cual continuar las investigaciones en la región de los lagos Tar y San Martín.

\section{AGRADECIMIENTOS}

A las familias Leyenda (Ea. La Maipú), Perazzo y Díaz (Eas. La Tercera y El Castillo), Vila Moret (Ea. La Angelita), Noble (Ea. Cach Aike), Leyenda (Ea. La Bernarda), Jordana (Ea. Río Meseta), Soria (Ea. La Vega), a Cielos Patagónicos (Ea. El Cóndor) y a los propietarios y personal de las Eas. Lago Tar y Los Cerros.

A la Comunidad de Tres Lagos y al Destacamento Lago San Martín de la Gendarmería Nacional. A Mariana Selva por su importante colaboración en el campo y a Pedro Tiberi por su ayuda en la confección de los mapas.

A Fabiana Martín y a un evaluador anómino por sus comentarios.

Las investigaciones se realizan con el apoyo de subsidios otorgados por la Universidad Nacional de la Patagonia Austral (UNPA-UARG A/183/2, A/213-1 y 29/A245-1), CONICET (PIP 6405) y ANPCyT 26295.

\section{BIBLIOGRAFÍA}

ASCHERO, C. 1975 rev. 1983. Ensayo para una clasificación morfológica de los instrumentos líticos aplicada a estudios tipológicos comparativos. Informe al CONICET.

ASCHERO, C. A., R. A. GOÑI, M. T. CIVALERO, R. L. MOLINARI, S. L. ESPINOSA, A. G .GURAIEB y C. T. BELLELLI. 2005. Holocenic Park: La arqueología del Parque Nacional Perito Moreno. Anales de Administración de Parques Nacionales XVII: 71-119.

AUER, V. y D. CAPPANNINI. 1957. La erosión en la región de los lagos San Martín y Tar. IDIA Marzo, pp. 7-27.

BAMONTE, F. 2008. Características ambientales del ecotono bosque-estepa durante el Holoceno medio (Santa Cruz, Argentina). Tesis de Licenciatura. Departamento de Biología. Facultad de Ciencias Exactas y Naturales. Universidad Nacional de Mar del Plata. Ms.
BARBERENA, R. 2002. Los Límites del Mar. Isótopos Estables en Patagonia Meridional. Sociedad Argentina de Antropología, Buenos Aires.

BARBERENA, R., A. F. ZANGRANDO, A. F. GIL, G. A. MARTÍNEZ, G. G. POLITIS, L. A. BORRERO y G. A. NEME. 2009. Guanaco (Lama guanicoe) isotopic ecology in southern South America: spatial and temporal tendencies, and archaeological implications. Journal of Archaeological Science 36 (12): 2666-2675.

BEHRENSMEYER, A. K. 1978. Vertebrate Preservation in Fluvial Channels. Palaeogeography, Palaeoclimatology and Palaeoecology 63:83-199.

BELARDI, J. B., L. A. BORRERO, P. CAMPAN, F. CARBALLO MARINA, N. V. FRANCO, M. F. GARCÍA, V. D. HOROWITZ, J. L. LANATA, F. M. MARTÍN, F. MUÑOZ, S. MUÑOZ Y F. SAVANTI. 1992. Intensive Archaeological Survey in the Upper Santa Cruz Basin, Southern Patagonia. Current Anthropology 33 (4):451- 455

BELARDI, J. B. y P. CAMPAN. 1999. Estepa y bosque: la utilización de lagos y lagunas en la región de lago Argentino (Provincia de Santa Cruz). En Soplando en el viento. Actas de las III Jornadas de Arqueología de la Patagonia, editado por el Instituto Nacional de Antropología y Pensamiento Latinoamericano y la Universidad Nacional del Comahue, pp. 25-41. Neuquén y Buenos Aires.

BELARDI, J. B. y P. CAMPAN. 2009. Resultados arqueológicos en el Campo de Bloques 2, margen sur del lago San Martín (Provincia de Santa Cruz). En Arqueología de la Patagonia: una mirada desde el último confín, editado por M. Salemme, F. Santiago, M. Alvarez, E. Piana, M. Vázquez y E. Mansur, Tomo 2. pp. 927-939. Editorial Utopías, Ushuaia.

BELARDI, J. B. y M. S. CARACOTCHE. 2005. Resultados arqueológicos en el noroeste del lago Viedma, Provincia de Santa Cruz. En Actas del XIII Congreso Nacional de Arqueología Argentina, Tomo 4: 81-88. Córdoba.

BELARDI, J. B., F. CARBALLO MARINA, T. J. BOURLOT y A. RE. 2009. Paisajes arqueológicos, circulación e interacción en diferentes escalas: una perspectiva desde el lago Tar (Provincia de Santa Cruz). En Arqueología de la Patagonia: una mirada desde el último confín, editado por M. Salemme, F. Santiago, M. Alvarez, E. Piana, M. Vázquez y E. Mansur, Tomo 1. pp. 219-231. Editorial Utopías, Ushuaia.

BELARDI, J. B., S. ESPINOSA, F. CARBALLO MARINA, G. BARRIENTOS, R. A. GOÑI, A. SÚNICO, T. BOURLOT, C. PALLO, A. RE y P. CAMPAN. 2007. Integración de 
las cuencas de los lagos Tar y San Martín (Provincia de Santa Cruz) a la dinámica del poblamiento humano del sur de Patagonia: primeros resultados. XVI Congreso Nacional de Arqueología Argentina. San Salvador de Jujuy.

BELARDI, J. B. y R. A. GOÑI. 2006. Representaciones rupestres y convergencia poblacional durante momentos tardíos en Santa Cruz (Patagonia argentina). El caso de la meseta del Strobel. En Tramas en la Piedra. Producción y usos del arte rupestre, editado por D. Fiore y M. M. Podestá, pp. 85-94. World Archaeological Congress, Sociedad Argentina de Antropología y Asociación Amigos del Instituto Nacional de Antropología, Buenos Aires.

BELARDI, J. B., P. TIBERI, C. STERN y A. SÚNICO. 2006. Al este del cerro Pampa: ampliación del área de disponibilidad de obsidiana de Pampa del Asador (Provincia de Santa Cruz). Intersecciones en Antropología 7: 27-36.

BELÇAGUY, H. 1983. Tipología de los materiales líticos del médano Estancia Cach-Aike - colección Thierauf - sitios 31, 48 y 49 - lago San Martín - provincia de Santa Cruz. Tesis de Licenciatura en Ciencias Antropológicas. Facultad de Filosofía y Letras, Universidad de Buenos Aires. Ms

BONARELLI, G. y J J. NAGERA. 1921. Observaciones geológicas en las inmediaciones del lago San Martín (Territorio de Santa Cruz) Boletín Ministerio de Agricultura. Dirección General de Minas, Geología e Hidrología Serie B (Geología) № 27.

BORRERO, L. A. 1989-1990. Evolución divergente en la Patagonia Austral. Anales del Instituto de la Patagonia. Serie Ciencias Humanas 19: 133-140.

BORRERO, L. A. 1994-1995. Arqueología de la Patagonia. Palimpsesto. Revista de Arqueología 4: 9-69.

BORRERO, L. A. 1998. (Compilador). Arqueología de la Patagonia meridional (Proyecto Magallania), pp.11-17. Ediciones Búsqueda de Ayllu, Concepción del Uruguay.

BORRERO, L. A. 2004. The Archaeozoology of Andean 'Dead Ends' in Patagonia: Living near the Continental Ice Cap. En Colonisation, Migration and Marginal Areas. A Zooarchaeological approach, editado por M. Mondini, A. S. Nuñoz y S. Wickler. pp 55-61. Oxbow Books, Oakville.

BORRERO, L. A. y N. V. FRANCO. 1997. Early Patagonian Hunters-Gatherers: Subsistence and Technology. Journal of Anthropological Research 53:219-239.

BORRERO, L. A. y N. V. FRANCO. 2000. Curso superior del río Santa Cruz: perspectivas temporales. En Desde el País de los Gigantes. Perspectivas arqueológicas en Patagonia, editado por la Universidad Nacional de la Patagonia Austral, Tomo I: 109-122. La Plata.
BORRERO L. A., R. GUICHON, R. TYKOT, J. KELLY, A. PRIETO y P. CÁRDENAS. 2001. Dieta a partir de isótopos estables en restos óseos humanos de Patagonia austral. Estado actual y perspectivas. Anales Instituto de la Patagonia, 29:119-127.

BORRERO, L. A. y L. M. MANZI. 2007. Arqueología supraregional y biogeografía en Patagonia meridional. En Arqueología de Fuego-Patagonia. Levantando piedras, desenterrando huesos... y develando arcanos, editado por F. Morello, M. Martinic, A. Prieto y G. Bahamonde, pp. 411- 419. Ediciones CEQUA, Punta Arenas.

BORRERO, L. A. y A. S. MUÑOZ. 1999. Tafonomía en el bosque patagónico: Implicaciones para el estudio de su explotación y uso por poblaciones humanas de CazadoresRecolectores. En Soplando en el viento. Actas de las III Jornadas de Arqueología de la Patagonia, editado por el Instituto Nacional de Antropología y Pensamiento Latinoamericano y la Universidad Nacional del Comahue, pp. 43-56. Neuquén y Buenos Aires.

CASIRAGUI, M. y M. CAORSI. 2000. Retratos. Patagonia sur. Grupo Abierto Comunicaciones, Buenos Aires.

CIVALERO, M. T. y C. A. ASCHERO. 2003. Early occupations al Cerro Casa de Piedra 7, Santa Cruz Province, Patagonia, Argentina. En Where the South Winds Blow. Ancient Evidence of Paleo South Americans, editado por L. Miotti, M. Salemme y N. Flegenheimer, pp.141-148. Texas A\&M University, Texas.

CIVALERO, M. T. y N. V. FRANCO. 2003. Early Occupations in Western Santa Cruz Province, Southermost South America. Quaternary International 109-110:77-86.

CORDERO, R., H. O. PANARELLO, S. LANZELOTTI y C. M. FAVIER DUBOIS. 2003. Radiocarbon age offsets between living organisms from marine and continental reservoir in coastal localities of Patagonia (Argentina). Radiocarbon 45 (1): 9-15.

De NIGRIS, M., M. J. FIGUERERO TORRES, A. G. GURAIEB y G. L. MENGONI GOÑALONS. 2004. Nuevos fechados radiocarbónicos de la localidad de Cerro de los Indios I (Santa Cruz) y su proyección areal. En Contra viento y marea. Arqueología de Patagonia, editado por T. Civalero, P. Fernández y G. Guraieb, pp. 537-544. Instituto Nacional de Antropología y Pensamiento Latinoamericano, Buenos Aires.

DUNNELL, R. C. y W. DANCEY. 1983. The siteless survey: A regional scale data collection strategy. Advances in Archaeological Method and Theory, editado por M. Schiffer, 6:267-287. Academic Press, New York.

ESPINOSA, S. L. 2000. Los conjuntos artefactuales líticos de la estepa y del bosque en el Parque Nacional Perito 
Moreno (Santa Cruz, Argentina). En Desde el País de los Gigantes. Perspectivas arqueológicas en Patagonia, editado por la Universidad Nacional de la Patagonia Austral, Tomo II: 357-367. La Plata.

ESPINOSA, S. 2002. Estrategias tecnológicas líticas y uso del espacio en momentos tardíos en el Parque Nacional Perito Moreno (Santa Cruz). Tesis doctoral FFyL, UBA. Ms.

ESPINOSA, S. L., J. B. BELARDI y R. MOLINARI. 2007. Análisis tecnológico de los artefactos líticos de la colección Horst Thierauf provenientes de las cuencas de los lagos Tar y San Martín (Provincia de Santa Cruz, Argentina). En Arqueología de Fuego-Patagonia. Levantando piedras, desenterrando huesos... y develando arcanos, editado por F. Morello, M. Martinic, A. Prieto y G. Bahamonde, pp. 675- 685. Ediciones CEQUA, Punta Arenas.

ESPINOSA, S. L., J. B. BELARDI Y A. SÚNICO. 2009. ¿Cuan al oeste? Arqueología del istmo de la península Maipú (lago San Martín, provincia de Santa Cruz) en su contexto regional. Arqueología 15: 187-205

ESPINOSA, S. L. y R. A. GOÑI. 1999. Viven! Una fuente de obsidiana en la Provincia de Santa Cruz. En Soplando en el viento. Actas de las III Jornadas de Arqueología de la Patagonia, editado por el Instituto Nacional de Antropología y Pensamiento Latinoamericano y la Universidad Nacional del Comahue, pp. 177-188. Neuquén y Buenos Aires.

FRANCO, N. V. y L. A. BORRERO. 2003. Chorrillo Malo 2: initial peopling of the upper Santa Cruz basin, Argentina. En Where the South Winds Blow. Ancient Evidence of Paleo South Americans, editado por L. Miotti, M. Salemme y N. Flegenheimer, pp.149-152. Texas A\&M University, Texas.

FRANCO, N. V. L. A. BORRERO, F. CARBALLO MARINA, J. B. BELARDI, F. M. MARTÍN, P. CAMPAN, C. FAVIER DUBOIS, M. I. HERNÁNDEZ, N. STADLER, H. CEPEDA, A. MUÑOZ, F. BORELLA e I. CRUZ. 1999. Arqueología del cordón Baguales y sistema lacustre al sur del lago Argentino. Praehistoria 3: 65-86.

FOLEY, R. 1981. Off-Site Archaeology and Human Adaptation in Eastern Africa. An Analysis of Regional Artefact Density in the Amboseli, Southern Kenia. Cambridge Monographs in African Archaeology 3. BAR International Series 97. Oxford.

GILLI, A., D. ARIZTEGUI, F. S. ANSELMETTI, J. A. MCKENZIE, V. MARKGRAF, I. HAJDA y R. D. MCCULLOCH. 2005. Mid-Holocene strengthening of the Southern Westerlies in South America-Sedimentological evidences from lago Cardiel, Argentina (495). Global and Planetary Change 49:75-93.
GOÑI, R. A. 1988. Arqueología de momentos tardíos en el Parque Nacional Perito Moreno (Santa Cruz, Argentina). En Precirculados de las ponencias científicas presentada a los simposios. IX Congreso Nacional de Arqueología Argentina, pp. 140-151. Facultad de Filosofía y Letras (UBA), Buenos Aires.

GOÑI, R. A., G. BARRIENTOS y G. CASSIODORO. 2000/2002.

Las condiciones previas a la extinción de las poblaciones humanas del sur de Patagonia: una discusión a partir del análisis de la estructura del registro arqueológico de la cuenca del Lago Salitroso. Cuadernos del Instituto Nacional de Antropología y Pensamiento Latinoamericano 19: 249-266.

GRADIN, C. 1996. Grabados y parapetos de la zona sur de la meseta del lago Buenos Aires (prov. de Santa Cruz). En Arqueología. Sólo Patagonia, editado por J. Gómez Otero, pp. 173-184. CENPAT-CONICET, Puerto Madryn.

KUHN, S. 1995. Mousterian Lithic Technology. An Ecological Perspoective. Princeton University Press, Princeton.

MELTZER, D. 1989. Was Stone Exchanged among Eastern North American Paleoindians? En Eastern Paleoindian Lithic Resource Use, editado por C. J. Ellis y J. Lothrop, pp: 11-39. Westview Press, Boulder.

MENGHIN, O. 1957. Estilos del arte rupestre de Patagonia. Acta Prehistórica 1:57-87

MOLINARI, R. 1983. Tipología de los materiales líticos de Ea. Cach-Aike, Colección Thierauf, Lago San Martín, Provincia de Santa Cruz. Tesis de Liceciatura, Facultad de Filosofía y Letras, UBA. Ms.

MOLINARI, R. y S. ESPINOSA. 1999. Brilla tú, "diamante" loco... En Soplando en el viento. Actas de las III Jornadas de Arqueología de la Patagonia, pp. 189-198, editado por el Instituto Nacional de Antropología y Pensamiento Latinoamericano y Universidad Nacional del Comahue.

NAMI, H. 1986. Experimentos para el estudio de la tecnología bifacial de las ocupaciones tardías en el extremo sur de Patagonia Continental. PREP: Informes de Investigación 5:1-120.

NELSON, M. 1991. The Study of Technological Organization. En Archaeological Method and Theory, editado por M. B. Schiffer, pp. 3:57-100. University of Arizona Press, Tucson.

PALMQVIST, P., D. R. GRÖCKE, A. ARRIBAS y A. FARINÄ. 2003. Paleoecological reconstruction of a lower Pleistocene large mammal community using biogeochemical $\left(\delta^{13} \mathrm{C}, \delta^{15} \mathrm{~N}, \delta^{18} \mathrm{O} \mathrm{Sr}: \mathrm{Zn}\right)$ and ecomorphological approaches. Paleobiology 29: 205-229.

PALLO, C. 2008. El conjunto lítico del sitio Bloque 1-Oquedad (Lago San Martín, SO de la provincia de Santa 
Cruz - Argentina). Tesis de Licenciatura en Ciencias Antropológicas. Facultad de Filosofía y Letras, Universidad de Buenos Aires. Ms

PALLO, C. 2009. La tecnología lítica del sitio Bloque 1-Oquedad (lago San Martín, Provincia de Santa Cruz). Resultados de la primera etapa de análisis. En Arqueología de la Patagonia: una mirada desde el último confín, editado por M. Salemme, F. Santiago, M. Alvarez, E. Piana, M. Vázquez y E. Mansur, Tomo 1. pp. 369-381. Editorial Utopías, Ushuaia.

RABASSA, J. y A. CORONATO. 2002. Glaciaciones del Cenozoico Tardío. En Geología y recursos naturales de Santa Cruz, editado por Miguel Haller, pp. 303315. Relatorio del XV Congreso Geológico Argentino. Buenos Aires.

SPONHEIMER, M., J. A. LEE-THORP, D. J. DERUITER, J.M. SMITH, N. J. VAN DER MERWE, K. REED, C. C. GRANT, L .K. AYLIFFE, T. F. ROBINSON, C. HEIDELBERGER y W. MARCUS. 2003. Diets Of Southern African Bovidae: Stable Isotope Evidence. Journal of Mammalogy, 84(2):471-479.
STERN, C. 1999. Black Obsidian from Central -South Patagonia: chemical characteristics, sources and regional distribution of artifacts. En Soplando en el viento. Actas de las III Jornadas de Arqueología de la Patagonia, editado por el Instituto Nacional de Antropología y Pensamiento Latinoamericano y la Universidad Nacional del Comahue, pp. 221-234. Neuquén y Buenos Aires.

STINER, M. 1991. Food procurement and transport by human and non-human predators. Journal of Archaeological Science 18:455-482.

TESSONE A, A. F. ZANGRANDO, G. BARRIENTOS, R. GOÑI, H. O. PANARELLO y M. CAGNONI. 2009. Stable Isotope Studies in the Salitroso Lake Basin (Southern Patagonia, Argentina): Assessing Diet of Late Holocene Hunter-gatherers. International Journal of Osteoarchaeology 19: 297-308.

WENZENS, G. 1999. Fluctuations of Outlet and Valley Glaciers in the Southern Andes (Argentina) during the Past 13,000 Years. Quaternary Research 51:238-247. 